\title{
Plasticity of Intact Rubral Projections Mediates Spontaneous Recovery of Function after Corticospinal Tract Injury
}

\author{
[Chad S. Siegel, ${ }^{1}$ Kathren L. Fink, ${ }^{1}$ Stephen M. Strittmatter, ${ }^{1,2}$ and ${ }^{\oplus W}$ William B.J. Cafferty ${ }^{1}$ \\ ${ }^{1}$ Department Of Neurology and ${ }^{2}$ Program in Cellular Neuroscience, Neurodegeneration and Repair, Yale University School of Medicine, New Haven, \\ Connecticut 06520
}

\begin{abstract}
Axons in the adult CNS fail to regenerate after injury, and therefore recovery from spinal cord injury (SCI) is limited. Although full recovery is rare, a modest degree of spontaneous recovery is observed consistently in a broad range of clinical and nonclinical situations. To define the mechanisms mediating spontaneous recovery of function after incomplete SCI, we created bilaterally complete medullary corticospinal tract lesions in adult mice, eliminating a crucial pathway for voluntary skilled movement. Anatomic and pharmacogenetic tools were used to identify the pathways driving spontaneous functional recovery in wild-type and plasticity-sensitized mice lacking Nogo receptor 1 . We found that plasticity-sensitized mice recovered $50 \%$ of normal skilled locomotor function within 5 weeks of lesion. This significant, yet incomplete, spontaneous recovery was accompanied by extensive sprouting of intact rubrofugal and rubrospinal projections with the emergence of a de novo circuit between the red nucleus and the nucleus raphe magnus. Transient silencing of this rubro-raphe circuit in vivo via activation of the inhibitory DREADD (designer receptor exclusively activated by designer drugs) receptor hM4di abrogated spontaneous functional recovery. These data highlight the pivotal role of uninjured motor circuit plasticity in supporting functional recovery after trauma, and support a focus of experimental strategies on enhancing intact circuit rearrangement to promote functional recovery after SCI.
\end{abstract}

Key words: plasticity; regeneration; spinal cord injury

\section{Introduction}

Spinal cord injury (SCI) results in irreversible devastating functional impairments. Damaged axons fail to regenerate after SCI due to the inhibitory environment in the mature CNS (Yiu and $\mathrm{He}, 2006$ ) and the low intrinsic growth capacity of adult neurons (Liu et al., 2011). There are two classes of inhibitory molecules, myelin-associated inhibitors and chondroitin sulfate proteoglycans (CSPGs) that signal through Nogo receptors 1 and 3 (Fournier et al., 2001; Liu et al., 2002; Venkatesh et al., 2005; Dickendesher et al., 2012), paired immunoglobulin-like receptor B (PirB) (Atwal et al., 2008), and protein tyrosine phosphatase sigma (PTPo) (Shen et al., 2009; Fry et al., 2010). Previously, intrinsic factors that restrict the growth potential of injured CNS neurons were identified, including phosphatase and tensin homolog (PTEN) (Park et al., 2008; Liu et al., 2010) and Kruppellike factor 7 (KLF7) (Moore et al., 2009). Antagonizing the influence of these factors either genetically (Kim et al., 2004; Cafferty et al., 2010; Liu et al., 2010; Dickendesher et al., 2012; Bartus et al., 2014) or pharmacologically (Schnell and Schwab, 1990; Bradbury et al., 2002; GrandPre et al., 2002; Li et al., 2004; Wang

Received Sept. 3, 2014; revised Nov. 25, 2014; accepted Dec. 3, 2014.

Author contributions: C.S.S., S.M.S., and W.B.J.C. designed research; C.S.S., K.L.F., and W.B.J.C. performed research; C.S.S., K.L.F., and W.B.J.C. analyzed data; C.S.S., K.L.F., S.M.S., and W.B.J.C. wrote the paper.

This work was supported by NIH Grant R01NS080388 and the Falk Medical Research Trust (S.M.S.)

S.M.S. is a cofounder of Axerion Therapeutics, seeking to develop NgR- and PrP-based therapeutics.

Correspondence should be addressed to William B. J. Cafferty, Department of Neurology, Yale University School of Medicine, 8300F 300 George Street, New Haven, CT 06536. E-mail: william.cafferty@yale.edu.

DOI:10.1523/JNEUROSCI.3713-14.2015

Copyright $\odot 2015$ the authors $\quad 0270-6474 / 15 / 351443-15 \$ 15.00 / 0$ et al., 2006, 2011) has shown some increase in axon regeneration; however, functional restoration remains partial.

Common to SCI models is a detectable degree of functional recovery without intervention, despite the absence of longdistance regeneration of the main descending motor pathway, the corticospinal tract (CST). Therefore, plasticity or localized sprouting of axotomized or intact spinal and supraspinal axons is hypothesized to drive spontaneous functional recovery. Indeed, localized compensatory sprouting of axotomized CST axons rostral to the lesion site forming de novo relay connections with long propriospinal neurons has been shown to drive spontaneous locomotor recovery in an activity-dependent manner after dorsal (Bareyre et al., 2004) and lateral (Courtine et al., 2008) hemisection. Furthermore, neuroprosthetic approaches that combine electrochemical stimulation of deafferented lumbar-sacral circuits with partial body weight supported treadmill training (Courtine et al., 2009) and robotic postural lateral and vertical trunk support (van den Brand et al., 2012) have shown significant functional recovery of locomotion after more severe SCI mediated via priopriospinal relay connections bridging the lesion site. However, less is known about the capacity of intact spinal and supraspinal circuits to drive spontaneous functional recovery after SCI. Intact premotor pathways, including the rubrospinal, reticulospinal, and vestibulospinal, have been suggested to mediate spontaneous locomotor recovery after mild thoracic spinal contusion, as retrograde tracing of these nuclei from lumbar spinal cord, together with locomotor recovery, is lost after moderate contusion. Furthermore, our previous data have shown that the 
intact CST sprouts into the denervated side of the spinal cord after unilateral CST lesion (Cafferty and Strittmatter, 2006), and elevating plasticity within this circuit by deleting Nogo receptor 1 (NgR1) enhances sprouting and elevates functional recovery. Similarly, augmenting plasticity of intact axons by suppressing PTEN (Liu et al., 2010), overexpressing KLF (Blackmore et al., 2012), delivering brainderived neurotrophic factor (Ueno et al., 2012), or degrading CSPGs with chondroitinase ABC (Starkey et al., 2012) has been observed. Enhanced restoration of forelimb function has also been observed after stimulating plasticity in corticofugal projections after unilateral CST lesion (Z'Graggen et al., 1998, 2000; Raineteau et al., 1999). Together, these studies suggest that plasticity of intact axons is a potent substrate to restore function after SCI.

In this study, we used a combination of behavioral, anatomical, and in vivo pharmacogenetic neuronal silencing to ascertain the mechanisms driving spontaneous recovery of function after partial SCI. We identified a novel connection between the red nucleus and the nucleus raphe magnus (NRM) that drives spontaneous restitution of function after complete CST lesion, and furthermore, elevating plasticity within this circuit enhances spontaneous functional recovery.

\section{Materials and Methods}

Mice

Adult (7-9 weeks of age) male $n g r 1^{-/-}$mice (described previously; Kim et al., 2004) back crossed with C57/BL6 mice for than nine generations and age matched C57/BL6 (Charles River Laboratories) wild-type $\left(n g r 1^{+/+}\right)$mice were used in this study. To minimize the number of animals used while maintaining enough rigor to achieve our scientific objectives (Festing and Altman, 2002), we used freely available power analysis (hedwig.mgh.harvard. edu/sample_size/js/js_parallel_quant.html) to estimate sample sizes. The experiments are powered at $90 \%$ based on the number of animals in each group, the standard deviation as determined by our preliminary grid-walking data (see Fig. 3A), and a significance level of 0.05 . Before behavioral assessment and surgery, mice were randomized and split into cages of three. These blocks were maintained unless evidence of fighting was apparent, upon which aggressors were housed singly.

\section{Surgery}

To complete bilateral pyramidotomy (bPyX) or sham lesion, mice were anesthetized with ketamine $(100 \mathrm{mg} / \mathrm{kg})$ and xylazine $(15 \mathrm{mg} / \mathrm{kg})$ and placed in a supine position, an incision was made to the left of the trachea, and blunt dissection exposed the occipital bone at the base of the skull. The occipital bone was removed on either side of the basilar artery with blunt Dumont \#2 forceps to expose the medullary pyramids. The dura mater was pierced with a 30 gauge needle and resected. The pyramids were transected bilaterally with fine Dumont $\# 5$ forceps to a depth of 0.25
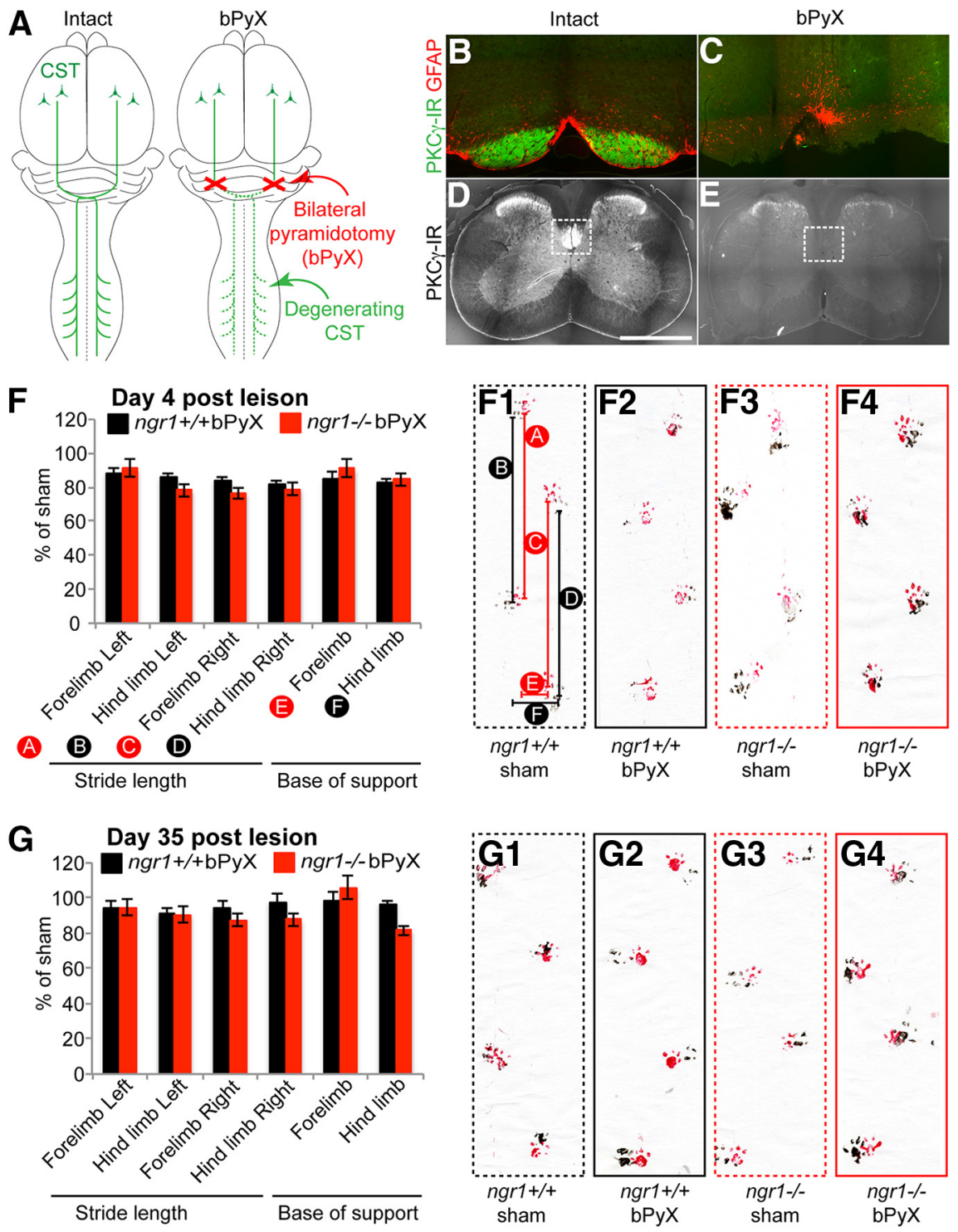

Figure 1. Bilateral pyramidotomy does not influence nonskilled locomotor function. $\boldsymbol{A}, \mathrm{A}$ schematic shows the location of the bPyX and degeneration of the CST. $\boldsymbol{B}-\boldsymbol{E}$, Photomicrographs of caudal brainstem and C7 spinal cord immunostained for PKC $\gamma$ show the intact corticospinal tract in the medullary pyramids $(\boldsymbol{B}$, green) and the spinal ventral dorsal column projection $(\boldsymbol{D}$, white) of $n g r 1^{+/+}$mice 4 weeks after sham lesion and its absence 4 weeks after bPyX $(\boldsymbol{C}, \boldsymbol{E})$. Intense GFAP immunoreactivity delineates the extent of the lesion and confirms its confinement to the pyramidal tract ( $\boldsymbol{C}$. $\boldsymbol{F}, \boldsymbol{G}$, Assessment of nonskilled locomotor function with footprint analysis revealed that neither $n g r 1^{+/+}\left(n=9\right.$, black bars) nor $n g r 1^{-/-}(n=9)$ mice displayed a functional deficit $4 \mathrm{~d}$ $(\boldsymbol{F})$ or $35 \mathrm{~d}(\boldsymbol{G})$ after bPyX in forelimb and hindlimb stride length or forelimb and hindlimb base of support compared to shamlesioned $n g r 1^{+/+}(n=7)$ and $n g r 1^{-/-}(n=8)$ controls. Gait parameters described in $\boldsymbol{F}$ are schematized in $\boldsymbol{F 1}$. Data are displayed as average distance in gait parameter as a percentage of sham \pm SEM. F1-F4, G1-G4, Examination of footprints (red ink applied to forelimbs and blank ink to hindlimbs) from $n g r 1^{+/+}(\boldsymbol{F 1}, \boldsymbol{F 2})$ and $n g r 1^{-/-}$mice $(\boldsymbol{F 3}, \boldsymbol{F} 4) 4 \mathrm{~d}$ after bPyX $(\boldsymbol{F} 2, \boldsymbol{F 4})$ or sham lesion $(\mathbf{F 1}, \mathbf{F 3})$, and $n g r 1^{+/+}(\mathbf{G 1}, \mathbf{G 2})$ and $n g r 1^{-/-}$mice $(\mathbf{G 3}, \mathbf{G 4}) 35 \mathrm{~d}$ after bPyX $(\mathbf{G} \mathbf{2}, \mathbf{G} 4)$ or sham lesion $(\mathbf{G 1}, \mathbf{G 3})$ shows no difference in stride length or base of support parameters (described in $\boldsymbol{F 1}$ ). Scale bar, $500 \mu \mathrm{m}$.

$\mathrm{mm}$ ( $n=18$ per genotype) or just exposed for sham lesion $(n=30$ per genotype). The wound was closed with 4.0 Vicryl suture. Four weeks after bilateral pyramidotomy, mice ( $n=24$ per genotype) were reanesthetized with ketamine/xylazine and given a unilateral microinfusion (Micro4; World Precision Instruments) of $100 \mathrm{nl}$ of a $10 \%$ solution of biotinylated dextran amine (BDA; 10,000 molecular weight; Invitrogen) over $3 \mathrm{~min}$ in the left red nucleus ( $3.5 \mathrm{~mm}$ posterior, $0.75 \mathrm{~mm}$ lateral, and $3.5 \mathrm{~mm}$ deep relative to Bregma). An additional cohort of mice ( $n=36$ per genotype) received a microinfusion of $75 \mathrm{nl}$ of the recombinant adeno-associated virus (AAV) rAAV2-hSyn-HA-hM4di-IRES-mCitrine (University of North Carolina Vector Core, Chapel Hill, NC) over 3 min into the nucleus raphe magnus $(-6.0 \mathrm{~mm}, 0.0 \mathrm{~mm}$ lateral, and $5.2 \mathrm{~mm}$ deep relative to 
A

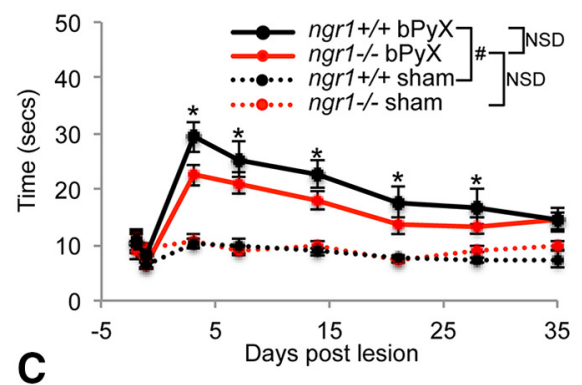

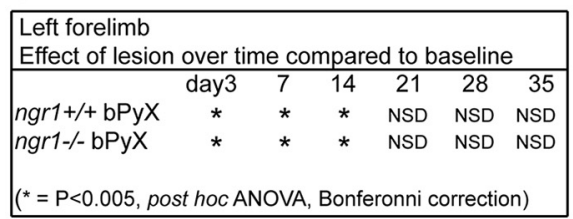

B

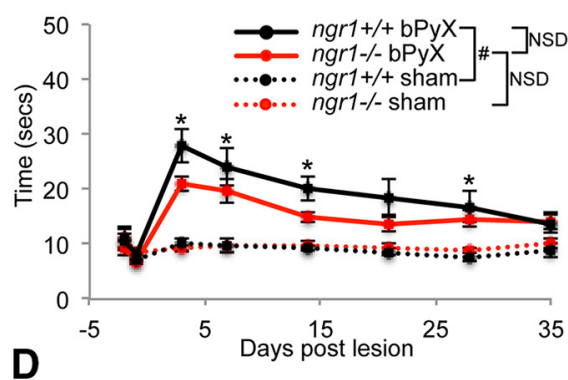

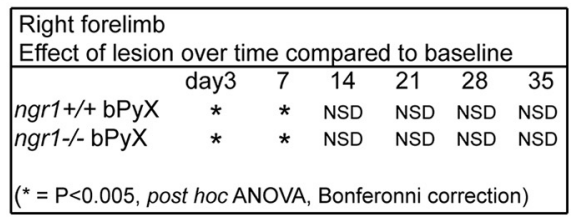

Figure 2. Bilateral pyramidotomy results in a transient deficit in skilled forelimb function. $A-D$, Skilled forelimb motor function was assessed using the tape removal task and analyzed using repeated-measures ANOVA with a Bonferroni correction for multiple comparisons $(\boldsymbol{A}, \boldsymbol{B})$ with post hoc ANOVA $(\boldsymbol{A}-\boldsymbol{D})$. Data are shown as the average time taken in seconds to remove the tape from each forelimb within each group \pm SEM. The time taken to remove the tape was significantly increased by the left forelimb $(\boldsymbol{A}$ ${ }^{\#} F_{(3,20)}=11.872, p<0.005$, post hoc; $\left.{ }^{*} p<0.005\right)$ and the right forelimb $\left(\boldsymbol{B},{ }^{\#} F_{(3,20)}=9.403, p<0.005\right.$, post hoc; $\left.{ }^{*} p<0.005\right)$ in $n g r 1^{+/+}$mice after bPyX $(\boldsymbol{A}, \boldsymbol{B}$, black lines; $n=7)$ compared to sham-lesioned controls (black stippled lines; $\left.n=6\right)$. Lesioninduced deficits failed to reach significance in the time taken to remove the tape by the left forelimb $(\boldsymbol{A} ; \mathrm{NSD}, p=0.09)$ or right forelimb ( $\boldsymbol{B} ; \mathrm{NSD}, p=0.061$ ) in $n g r 1^{-/-}$mice after bPyX (red lines; $n=7$ ) compared to sham-lesioned (red stippled lines; $n=$

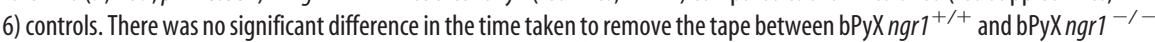
mice in either their left forelimb ( $\boldsymbol{A} ; \mathrm{NSD}, p=0.387$ ) or right forelimb ( $\boldsymbol{B} ; \mathrm{NSD}, p=0.44)$. Assessment of the effect of lesion over time within each group showed that both $n g r 1^{+/+}$and $n g r 1^{-/-}$mice displayed a significant lesion induced increase in the time taken to remove the tape after bPyX $\left({ }^{*} p<0.05\right)$ in both left $(\boldsymbol{C})$ and right forelimbs $(\boldsymbol{D})$. Both $n g r 1^{+/+}$and $n g r 1^{-/-}$demonstrated spontaneous restitution of function back to prelesion baseline levels by day 21 in the left forelimb $(\boldsymbol{C})$ and by day 14 in the right forelimb $(\boldsymbol{D})$.

Bregma) 3 weeks before bPyX or sham lesion. An investigator blinded to genotype completed all surgical procedures. All procedures and postoperative care were performed in accordance with the guidelines of the Institutional Animal Use and Care Committee at Yale University.

\section{Behavioral analysis}

All mice underwent three behavioral tests to assess their nonskilled locomotor function, skilled locomotor function, and skilled forelimb function before and after bilateral pyramidotomy. Mice were trained on each task for 1 week, and then presurgical baselines scores were collected. An experimenter blinded to genotype and treatment completed behavioral assessment and subsequent analysis.

Nonskilled locomotor function. Footprint analysis was used to assess nonskilled locomotor function (Duffy et al., 2012). Animals had waterbased nontoxic paint placed on the plantar surfaces of all four limbs (red on forelimbs and black on hindlimbs) and were then run three times along a 1-m-long narrow corridor lined with absorbent paper. Stereotyped gait and motor coordination parameters, including left and right forelimb and hindlimb stride length and forelimb and hindlimb base of support, were measured from three complete step cycles from the middle of the runway on days $-3,4,7,14,21,28$, and 35 after bilateral pyramidotomy ( $n=12$ per group) or sham lesion ( $n=8$ per group). Data are presented as the average distance of each parameter as a percentage of sham-lesioned controls \pm SEM. The Shapiro-Wilk test was used to assess whether data were normally distributed between genotypes at every time point studied.

Subsequently, data were analyzed with repeated-measures ANOVA with Bonferroni's correction for multiple comparisons.

Skilled locomotor function. Grid-walking analysis was used to assess skilled locomotor function (Starkey et al., 2005). Mice were placed on an elevated $45 \times 45 \mathrm{~cm}$ metal grid with $2.5 \times 2.5 \mathrm{~cm}$ square spacing covered by a dark box to make the environment more comfortable for the animals. Mice were videotaped via reflection from a mirror placed under the grid and allowed to explore the grid for $3 \mathrm{~min}$. Videos were scored for the percentage of impaired steps out of the first 50 steps for each limb indi- vidually. Impaired steps included a foot slip where the limb fell between the rungs or an incorrectly placed step where either the ankle or the tips of the digits were placed on the rung instead of proper grasping of the rung. Animals were tested $3 \mathrm{~d}$ before bilateral pyramidotomy for baseline function and 2, 4, 7, 14,21, 28, and $35 \mathrm{~d}$ after lesion. Data are presented per limb as the average percentage of the first 50 steps that were impaired \pm SEM. The Shapiro-Wilk test was used to assess whether data were normally distributed between genotypes at every time point studied. Subsequently, data were analyzed via repeated-measures ANOVA with Bonferroni's correction for multiple comparisons. Post hoc analysis was completed for statistically significant differences comparing the percentage of missteps at each time point between genotypes and the effect of lesion over time with ANOVA.

Skilled forelimb function. Tape removal was used to assess skilled forelimb function (Starkey et al., 2005). A small piece of adhesive tape was placed on the plantar surface of each forelimb. The time taken to sense the tape (animal shaking the limb and bringing the limb to the mouth) was recorded as the sensory score. The time taken to remove the tape from the forelimb was recorded as the motor score. A total of three trials were performed for each forelimb, with a maximum time limit of 3 min to sense and remove the tape. Animals were tested $3 \mathrm{~d}$ before bilateral pyramidotomy for baseline function and $2,4,7,14,21,28$, and $35 \mathrm{~d}$ post lesion $(\mathrm{dpl})$. Data are presented as the average time taken in seconds to sense and remove the tape \pm SEM. The Shapiro-Wilk test was used to assess whether data were normally distributed between genotypes at every time point studied.

Subsequently data were analyzed via repeated-measures ANOVA with Bonferroni's correction for multiple comparisons. Post hoc analysis was completed for statistically significant differences comparing the time taken to sense and remove the tape at each time point between genotypes and the effect of lesion over time with ANOVA.

Behavior after rAAV2-hSyn-HA-hM4Di-IRES-mCitrine injection into nucleus raphe magnus. Animals were injected with rAAV2-hSyn-HAhM4di-IRES-mCitrine into the NRM as described above $(n=36$ per genotype). Three weeks after injection, animals were randomized and split into two groups, a red group to assess anatomical distribution of hM4di ( $n=12$ per genotype) and a blue group to assess the functional impacts of hM4di activation ( $n=24$ per genotype; see Fig. $8 C$ ).

Grid-walking analysis was performed as described above on mice in the red group on day 21 after hM4di injection; however, 30 min before assessment, mice ( $n=6$ per genotype) received an intraperitoneal injection of either $0.2 \%$ DMSO in saline or clozapine $N$-oxide (CNO; $1 \mathrm{mg} / \mathrm{kg}$, Sigma-Aldrich; Rogan and Roth, 2011; Lee et al., 2014). Twenty-four hours after intraperitoneal injection, grid-walking analysis was repeated to assess the chronic effects of hM4di activation. Data are presented as the average percentage of missed steps made over 3 min \pm SEM. The ShapiroWilk test was used to assess whether data were normally distributed between genotypes and treatments at every time point studied. Subsequently, data were analyzed via ANOVA with Bonferroni's correction. Twenty-two days after hM4di injection, mice in the red group were treated intraperitoneally with either vehicle or $\mathrm{CNO}(n=6$ per genotype). Thirty minutes after treatment, animals were placed on an accelerating rotarod ( $1 \mathrm{rpm}$ with an acceleration of $0.1 \mathrm{rpm} / \mathrm{s}$ ) for $5 \mathrm{~min}$. Sixty minutes after the rotarod, mice were transcardially perfused and prepared for histological examination (as described below) of c-fos activity in the raphe nuclei (Sluka and Rasmussen, 2010) and the vestibular nuclei (Ruigrok et al., 1996; Sluka and Rasmussen, 2010). 
Three weeks after hM4di injection, mice in the blue group underwent either bilateral pyramidotomy ( $n=12$ per genotype) or sham lesion ( $n=12$ per genotype). On days $-5,4,7$, 14, 21, 28, and 35 after lesion (or sham), all mice underwent two sessions of grid-walking analysis separated by $2 \mathrm{~h}$. Thirty minutes before the first assessment period, all mice received an intraperitoneal injection of saline (as above). Thirty minutes before the second behavioral assessment period, all mice received an intraperitoneal injection of $\mathrm{CNO}$ (as above). Data are presented as average percentage of missteps made per limb during 3 min of grid walking \pm SEM. The Shapiro-Wilk test was used to assess whether the data were normally distributed between genotypes at every time point studied. Subsequently, data were and analyzed by two-way repeated-measures ANOVA with Bonferroni's correction for multiple comparisons. Post hoc analysis was completed for statistically significant differences comparing the percentage of missteps at each time point between genotypes, treatment, and the effect of lesion over time with ANOVA.

\section{Histology}

Mice were killed with an overdose of ketamine/ xylazine and were transcardially perfused with $0.9 \% \mathrm{NaCl}$ (normal saline) followed by $4 \%$ paraformaldehyde in PBS. Brains and spinal cords were dissected, postfixed in $4 \%$ paraformaldehyde overnight at $4^{\circ} \mathrm{C}$, and subsequently embedded in $10 \%$ gelatin (Sigma-Aldrich) dissolved in water for vibratome sectioning. Transverse sections $(35-40 \mu \mathrm{m})$ of cervical spinal cord (C6-C7) and brain including basilar pontine nuclei (BPNs) and raphe nuclei were processed for BDA with streptavidinconjugated secondary antibodies (Invitrogen) and tyramide signal amplification (PerkinElmer). Immunofluorescence used antibodies directed against 5-hydroxytryptamine (5-HT; 1:1000; ImmunoStar), green fluorescent protein (1: 5000; Invitrogen), protein kinase C- $\gamma$ (PKC $\gamma$; 1:200; Santa Cruz Biotechnology), c-Fos (1: 500; Santa Cruz Biotechnology), and glial fibrillary acidic protein (GFAP; 1:10,000; Dako) with Alexa Fluor 350, 488, and 594 (1: 100 for Alexa Fluor 350; 1:500 for Alexa Fluor 488 and 594; Invitrogen).

\section{Quantification of BDA-labeled axons}

Densitometric analysis of BDA-labeled axons traced from the red nucleus and terminating in the cervical spinal cord, pontine nuclei, and nucleus raphe magnus was completed in Image (version 1.48r; National Institutes of Health) as described previously (Cafferty and Strittmatter, 2006). Briefly, labeled axons were selected by thresholding, and the average fiber length was measured using the skeletonize function in five sections per animal. Data are presented as the average length of $\mathrm{BDA}+$ axons, in square millimeters, in each locus, and were analyzed by ANOVA with Bonferroni's correction.

\section{Quantification of 5-HT and c-fos positive cells in NRM and vestibular nuclei}

The cells located in the nucleus raphe magnus were labeled immunohistochemically with 5-HT. The number of 5-HT-positive cells and the number of 5-HT-positive cells expressing c-fos were quantified to determine the amount of functional inhibition of the NRM with $\mathrm{CNO}$ treatment.

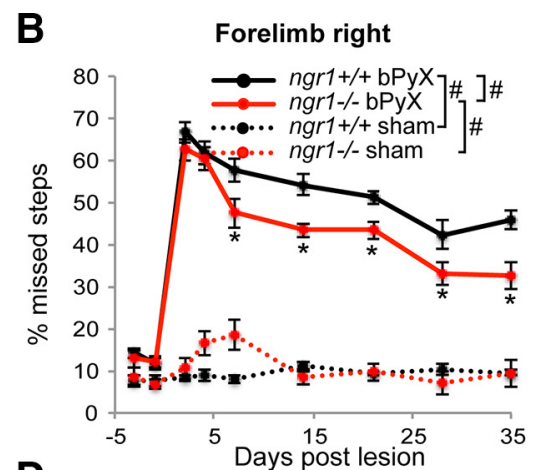

D

\begin{tabular}{|lccccccc|}
\hline Right forelimb \\
Recovery compared to initial & deficit at 2 & dpl \\
\hline \multicolumn{10}{|c}{ day4 } & 7 & 14 & 21 & 28 & 35 \\
$n g r 1+/+$ bPyX & NSD & NSD & $*$ & $*$ & $*$ & $*$ \\
$n g r 1-/-$ bPyX & NSD & $*$ & $*$ & $*$ & $*$ & $*$ \\
$\left({ }^{*}=\mathrm{P}<0.005\right.$, post hoc ANOVA, Bonferonni correction $)$ \\
\hline
\end{tabular}
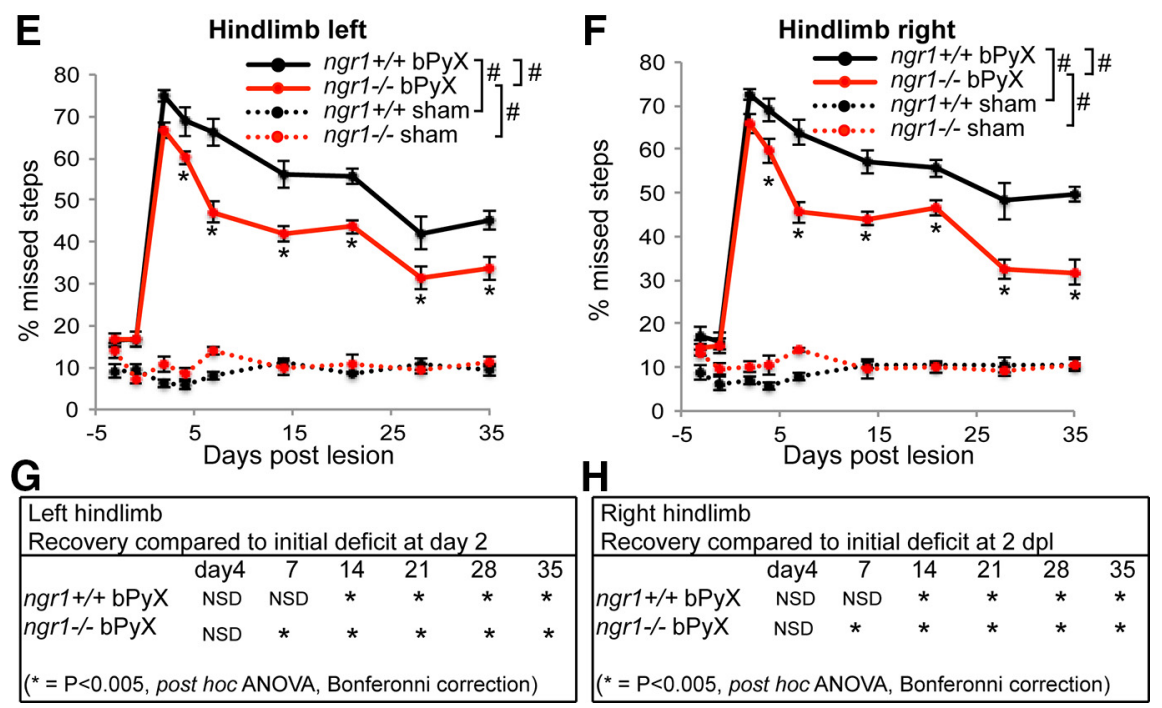

Figure 3. Bilateral pyramidotomy results in significant and sustained functional deficits in skilled locomotion. $\boldsymbol{A}-\boldsymbol{H}$, Skilled locomotion was assessed by counting the number of footfalls made during $3 \mathrm{~min}$ of grid walking on a $2.5 \times 2.5 \mathrm{~cm}$ mesh grid and analyzed using repeated-measures ANOVA with a Bonferroni correction for multiple comparisons $(\boldsymbol{A}, \boldsymbol{B}, \boldsymbol{E}, \boldsymbol{F})$, with post hoc ANOVA $(\boldsymbol{A}-\boldsymbol{H})$. Data are shown as the average number of missed steps expressed as a percentage of total steps made over 3 min \pm SEM percentage of missed steps made by the left forelimbs $\left(\boldsymbol{A} ;{ }^{\#} F_{(3,32)}=297.555, p<0.005\right)$, the right forelimbs $\left(\boldsymbol{B} ;{ }^{\#} F_{(3,32)}=\right.$ $210.306, p<0.005)$, the left hindlimbs $\left(\boldsymbol{E} ;{ }^{\#} F_{(3,32)}=265.443, p<0.005\right)$, and the right hindlimbs $\left(\boldsymbol{F} ;{ }^{\#} F_{(3,32)}=319.533, p<\right.$ significant function of all limbs compared to $n g r 1^{+/+}$mice after bPyX. ${ }^{\#} p<0.005$ with post hoc ANOVA; ${ }^{*} p<0.005 . C, D, G, H$ Assessment of the effect of lesion over time within each group showed that both $n g 1^{+/+}$and $n g r 1^{-/-}$mice showed a significant lesion-induced increase in the percentage of missed steps made by all limbs after bPyX that was sustained throughout the testing period. $\mathrm{Ngrl}^{+/+}$demonstrated significant spontaneous functional recovery in all limbs by $14 \mathrm{dpl}$ compared to the maximum deficits observed at $2 \mathrm{dpl}$. However, $n g r 1^{-1-}$ showed accelerated spontaneous functional recovery, as by day 7 after lesion they had already made significantly fewer errors compared to the maximum deficits observed at $2 \mathrm{dpl}$. ${ }^{*} p<0.005$.

The numbers of c-fos-positive cells were quantified in the vestibular nuclei bilaterally as a control for $\mathrm{CNO}$ and vehicle treatments. The vestibular nuclei were identified by morphology and comparison to Paxinos and Franklin's (2001) brain atlas (five sections per area per mouse; $n=3-4$ per group). Data are presented as the average number of $5-\mathrm{HT}+\mathrm{c}-$ fos + neurons in the $\mathrm{NRM} \pm \mathrm{SEM}$ and were analyzed by ANOVA with Bonferroni's correction.

\section{Results}

Complete recovery of overground locomotion and fine forelimb function after bilateral pyramidotomy

To dissect the pathways mediating spontaneous recovery of function after SCI, we used a bilateral pyramidotomy model (Fig. 1A). 


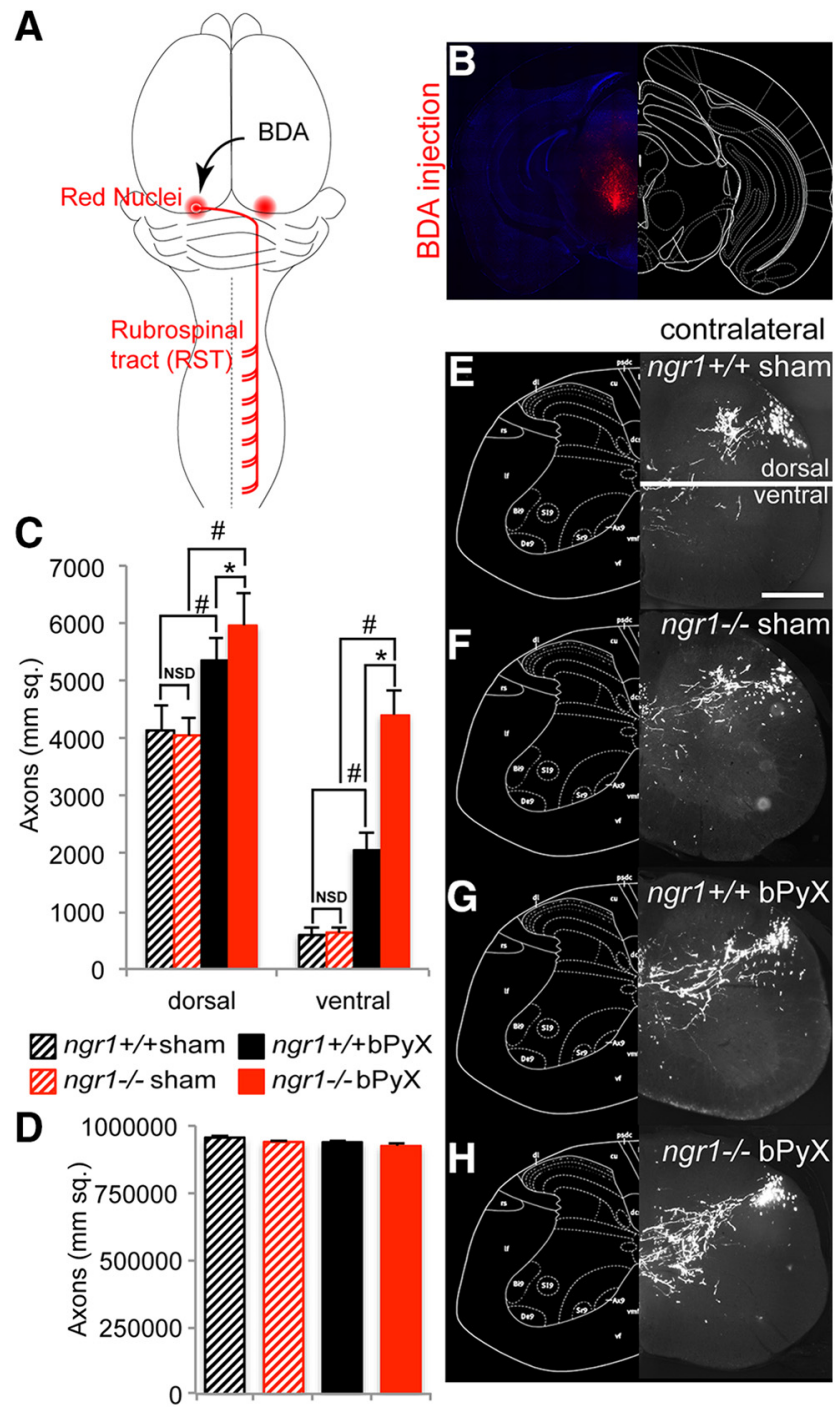

Figure 4. Bilateral pyramidotomy increases plasticity of the intact rubrospinal tract. $\boldsymbol{A}$, A schematic shows the location of the red nuclei, the location of the BDA injection, and the unilateral projection of the rubrospinal tract in the lateral funiculus of the spinal cord and its termination pattern at every spinal segment. $\boldsymbol{B}$, Photomicrograph shows a coronal section of brain (with corresponding plate from Paxinos and Franklin's (2001) mouse atlas) through the red nucleus 6 weeks after a $75 \mathrm{nl}$ stereotaxic microinjection of BDA (BDA, red; DAPI, blue). The discrete immunofluorescence confirms the fidelity of targeting the red nuclei specifically. $C, D$, Bar charts show average density of BDA+ RST axons per $\mathrm{mm}^{2}( \pm$ SEM) in the cervical spinal cord $(\boldsymbol{C})$ and $\mathrm{PnC}(\boldsymbol{D})$ in bPyX and sham-lesioned $n g r 1^{+1+}$ and $n g r 1^{-1-}$ mice. $\boldsymbol{E}-\boldsymbol{H}$, Photomicrographs show BDA + RST axons (with map of corresponding spinal segment) in the DLF and terminals in intermediate laminae in coronal sections of $C 7$ spinal cord of $n g r 1^{+/+}(\boldsymbol{E}, \boldsymbol{G})$ and $n g r 1^{-/-}(\boldsymbol{F}, \boldsymbol{H})$ mice after bPyX $(\boldsymbol{G}, \boldsymbol{H})$ and sham lesion $(\boldsymbol{E}, \boldsymbol{F})$. There was no significant difference in the density of BDA+ RST axons in the dorsal or ventral halves ( $\boldsymbol{E}$; delineated in line with the central canal) of the spinal cord at cervical segments $\left(6-C 8\right.$ between $n g r 1^{+/+}$and $n g r 1^{-/-}$mice after sham lesion ( $\boldsymbol{C}$; compare photomicrographs $\boldsymbol{E}, \boldsymbol{F}$ ). The density of BDA + RST axons was significantly elevated in both the dorsal and ventral halves of the spinal cord 6 weeks after bPyX in $n g r 1^{+/+}(n=11)$ and $n g r 1^{-/-}(n=11)$ mice compared to sham-lesioned $n g r 1^{+/+}$ $(n=9)$ and $n g r 1^{-/-}(n=9)$ mice $\left(\boldsymbol{C} ;{ }^{\#} p<0.005\right.$, ANOVA, compare $\boldsymbol{E}, \boldsymbol{G}$; compare $\left.\boldsymbol{F}, \boldsymbol{H}\right)$. Lesion-induced enhanced plasticity of BDA + RST axon terminals was significantly augmented in $n g r 1^{-1-}$ compared to $n g r 1^{+/+}$mice in both dorsal and ventral halves of the spinal cord 6 weeks after bPyX $\left(\boldsymbol{C} ;{ }^{*} p<0.005\right.$, ANOVA, compare $\left.\boldsymbol{G}, \boldsymbol{H}\right)$. Assessment of $\mathrm{BDA}+$ axon density in the pontine reticular nucleus revealed no significant difference in BDA tracing efficiency between genotypes after bPyX or sham lesion ( $D$; data are shown as density of BDA + axons per square millimeter \pm SEM). Scale bar, $100 \mu \mathrm{m}$.
This approach completely severs both sides of the corticospinal tract without interfering with any other motor or sensory pathways. The CST is incapable of spontaneous axon regeneration (Kim et al., 2004); therefore, functional restitution after bPyX would have to rely on compensation from alternate intact motor circuits. We showed previously that plasticity within intact CST circuits is enhanced after unilateral CST lesion [unilateral pyramidotomy (uPyX)] in NgR1 knock-out mice $\left(n g r 1^{-/-}\right.$) (Cafferty and Strittmatter, 2006). Therefore, we chose to complete these experiments in both wild-type $\left(n g r 1^{+/+}\right)$and plasticity-sensitized $n g r 1^{-/-}$mice, thus maximizing our ability to observe functionally meaningful structural changes.

Previous studies have shown that spontaneous recovery of motor function after SCI is task specific and dependent upon the identity of the descending motor tracts that have been interrupted (Raineteau and Schwab, 2001). Specifically, unilateral CST lesion has been shown to have no significant impact on skilled and nonskilled locomotion, but rather specifically impairs skilled forelimb function (Metz et al., 1998; Muir and Whishaw, 1999; Kanagal and Muir, 2009). Therefore, to explore the mechanisms that drive spontaneous recovery of function after complete CST lesion, we sought a behavioral paradigm that would demonstrate a significant lesion-induced deficit, followed by a period of modest but incomplete recovery. To this end, we used three behavioral tasks that would assess skilled forelimb function, nonskilled locomotor function, and skilled locomotor function using the forelimb adhesive tape removal task (Fig. $2 A-D$ ), footprint analysis (Fig. $1 F, G$ ), and grid-walking analysis (Fig. $3 A-H$ ), respectively.

To ensure that the CST was completely interrupted in all lesioned mice after bPyX, we immunostained coronal sections of brainstem through the lesion site and cervical spinal sections with antibodies to PKC $\gamma$ (Fig. $1 B-E$ ). PKC $\gamma$ is expressed in the intact CST (Cafferty and Strittmatter, 2006) and can be seen in the pyramids (Fig. $1 B$ ) and the ventral dorsal columns in intact mice (D). PKC $\gamma$ staining is abolished in the ventral brainstem and dorsal columns after bPyX, confirming complete ablation of the CST (Fig. 1C,E). Previous studies have highlighted the confounding potential of severe lesions when targeting the CST with pyramidotomy (Whishaw et al., 1993); therefore, we stained brainstem sections with antibodies to GFAP to assess the extent of the lesion. Careful inspection of the lesion site revealed that intense GFAP immunoreactivity (Fig. 1C) was confined to the pyramidal tract, suggesting that underlying structures remained intact in all animals that received bPyX.

Stereotyped locomotor parameters (Fig. 1) assessed via footprint analysis showed that neither $n g r 1^{+/+}$nor $\mathrm{ngrl}^{-/-}$displayed a lesion-induced deficit in stride length or base of support at either $4 \mathrm{~d}$ (Fig. $1 F$ ) or $35 \mathrm{~d}(G)$ after bPyX compared with sham lesion. These data are in agreement with previous reports showing that complete CST lesions do not cause measurable deficits in nonskilled locomotion (Metz et al., 1998; Muir and Whishaw, 1999; Kanagal and Muir, 2009), suggesting that the CST contributes little to this function and/or that compensation from redundant intact extrapyramidal pathway(s) is maintaining normal nonskilled locomotor function after complete axotomy of the CST.

Assessment of fine forelimb function using the tape removal task showed that neither $n g r 1^{+/+}$nor $n g r 1^{-1-}$ mice showed a deficit in the time taken to sense the presence of the adhesive tape after complete CST lesion compared to sham-lesioned controls (data not shown). The time taken to remove the tape was significantly increased after bPyX in $n g r 1^{+/+}$mice compared with 
sham-lesioned controls (Fig. $2 A, B ; p<$ 0.005 , repeated-measures ANOVA with Bonferroni's correction for multiple comparisons, with post hoc ANOVA). However, $n g r 1^{-1-}$ mice failed to show a significant lesion-induced deficit in the time taken to remove the tape after bPyX with either their left [Fig. 2A; no significant difference (NSD), $p=0.09$, repeated-measures ANOVA with Bonferroni's correction for multiple comparisons] or right forelimb (Fig. $2 B$; NSD, $p=$ 0.061 , repeated-measures ANOVA with Bonferroni's correction for multiple comparisons) compared to sham-lesioned controls. Furthermore, there was no significant difference in the time taken to remove the tape between bPyX $n g r 1^{+/+}$and bPyX $n g r 1^{-/-}$mice in either their left forelimb (Fig. 2A; NSD, $p=0.387$, repeated-measures ANOVA with Bonferroni's correction for multiple comparisons) or right forelimb (Fig. $2 B ; p=0.44$, repeated-measures ANOVA with Bonferroni's correction for multiple comparisons). Assessing the effect of bPyX over time within each group showed that both $n g r 1^{+/+}$and $n g r 1^{-/-}$mice showed a significant increase in the time taken to remove the adhesive tape immediately after lesion by both left (Fig. 2C; $p<0.005$ ) and right forelimbs $(D ; p<0.005)$. However, both $n g r 1^{+/+}$and $n g r 1^{-/-}$mice (Fig. $2 C, D)$ demonstrated spontaneous recovery of function back to prelesion baseline levels by $21 \mathrm{dpl}$ in the left forelimb (Fig. $2 C)$ and by $14 \mathrm{dpl}$ in the right forelimb (D). Owing to the initial functional deficits observed in both $n g r 1^{+/+}$and $n g r 1^{-/-}$mice, restitution of function in this behavioral task does not appear to be driven entirely by a redundant motor pathway, as in the case of nonskilled locomotion after bPyX (Fig. 1). Rather, the slow emergence of spontaneous functional recovery points to a mechanism that is driven in part by anatomical changes. However, the modest deficits and complete restitution of function over time suggest that this behavioral task lacks the sensitivity that would allow us to differentiate between these two mechanisms. Therefore, we sought to identify a behavioral task that shows gradual improvement over time but remains significantly impaired.

\section{Spontaneous recovery of skilled locomotor function is enhanced in plasticity-sensitized adult mice after bilateral pyramidotomy}

Assessment of skilled locomotion using grid-walking analysis revealed that all four limbs in $n g r 1^{+/+}$mice showed a significant increase in the percentage of missed steps made over 3 min after bPyX (Fig. $3 A, B, E, F$, black lines; $p<0.005$, repeated-measures ANOVA with Bonferroni's correction for multiple comparisons) compared to sham-lesioned controls (stippled black lines). Although post hoc analyses revealed that $n g r 1^{+/+}$mice maintained significant functional deficits throughout the testing period $(p<$
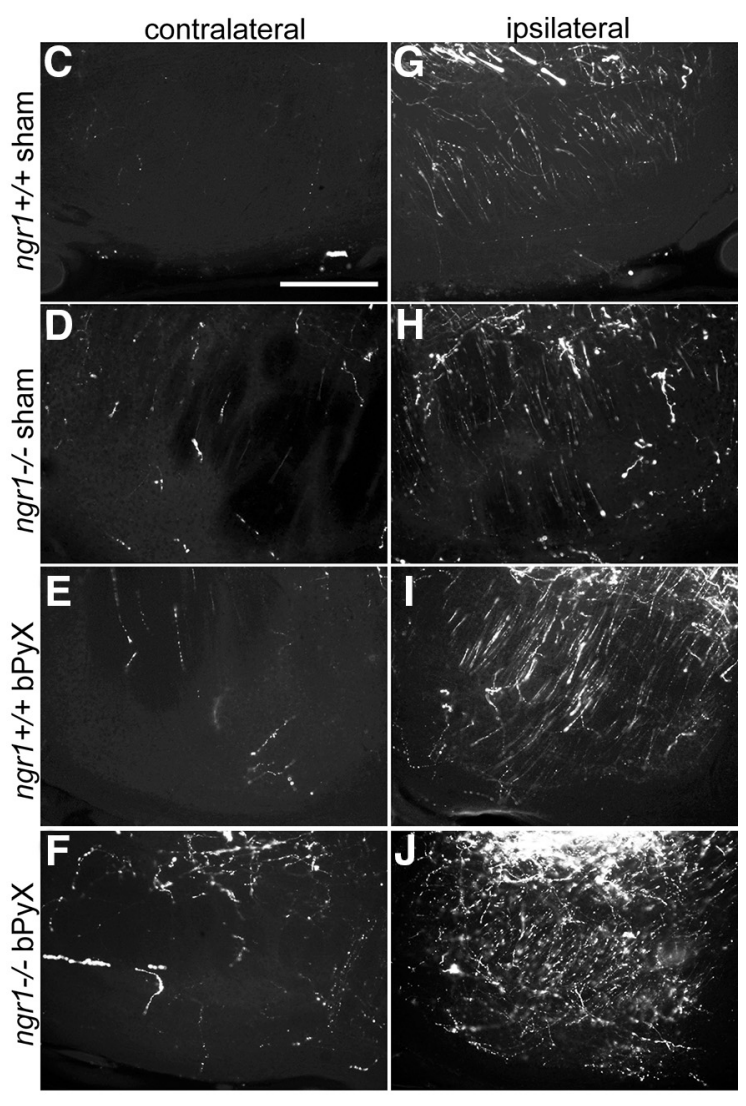

ipsi

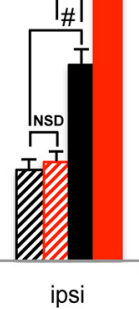

Figure 5. Bilateral pyramidotomy increases plasticity of intact rubrofugal terminals in the basilar pontine nuclei. $A$, A schematic shows the location of the BPNs, the site of unilateral BDA injection into the red nucleus, and the innervation pattern of rubropontine axons (red stippled line) into the BPNs. $B$, Bar chart shows average density of BDA + rubropontine axons per $\mathrm{mm}^{2}( \pm S E M)$ in BPNs BPNs contralateral $(\boldsymbol{C}-\boldsymbol{F})$ and ipsilateral $(\boldsymbol{G}-\boldsymbol{J})$ to the unilateral BDA injection into the red nucleus in $n g r 1^{+/+}(\boldsymbol{C}, \boldsymbol{G}, \boldsymbol{E}, \boldsymbol{I})$ and $(\boldsymbol{D}, \boldsymbol{H}, \boldsymbol{F}, \boldsymbol{J})$ mice after sham $(\boldsymbol{C}, \boldsymbol{D}, \boldsymbol{G}, \boldsymbol{H})$ or bPyX $(\boldsymbol{E}, \boldsymbol{F}, \boldsymbol{I}, \boldsymbol{J})$ lesion. There was no significant difference in the density of mice after sham lesion. The density of BDA + rubropontine axons was significantly elevated in both the contralateral and ipsilateral BPNs 6 weeks after bPyX in $n g r 1^{+/+}$and $n g r 1^{-/-}$mice compared to sham-lesioned $n g r 1^{+/+}$and $n g r 1^{-/-}$mice $\left(\boldsymbol{B} ;{ }^{\#} p<\right.$ 0.005, ANOVA; compare $\boldsymbol{C}, \boldsymbol{G}$ and $\boldsymbol{E}, \boldsymbol{I}$; compare $\boldsymbol{D}, \boldsymbol{H}$ and $\boldsymbol{F}, \boldsymbol{J})$. Lesion-induced enhanced plasticity of BDA + rubropontine axon terminals was significantly augmented in $n g r 1^{-/-}$compared to $n g r 1^{+/+}$mice in both contralateral and ipsilateral BPNs 6 weeks after bPyX $\left(\boldsymbol{B} ;{ }^{*} p<0.005\right.$, ANOVA; compare $\boldsymbol{E}, \boldsymbol{F}$; compare $\left.\boldsymbol{I}, \boldsymbol{J}\right)$. Scale bar, $100 \mu \mathrm{m}$.

0.05, ANOVA with Bonferroni's correction), $n g r 1^{+/+}$mice began to show significant spontaneous recovery of function by $14 \mathrm{dpl}$ (Fig. 3C, D, G, H; $p<0.005$, ANOVA with Bonferroni's correction), and by $35 \mathrm{dpl}$ had recovered to almost $25 \%$ of baseline levels. The maintained functional deficit observed in this task by wild-type mice suggests that functional redundancy with an intact motor pathway is minimal and points to structural plasticity as central in driving spontaneous partial restoration of function. Crucially, this observation allowed us to ask whether enhancing plasticity within remaining intact circuits could augment spontaneous recovery of function. Indeed, $n g r 1^{-/-}$mice recovered significant function in all limbs compared with $n g r 1^{+/+}$mice after bPyX (Fig. 3A,B,E,F; repeated-measures ANOVA with Bonferroni's correction for multiple comparisons, with post hoc ANOVA, $p<0.005)$. Similar to $n g r 1^{+/+}$mice, temporal assessment of spontaneous functional recovery revealed that $n g r 1^{-/-}$ mice displayed significant functional impairments throughout the testing period ( $p<0.05$, ANOVA, with Bonferroni's correction). However, $n g r 1^{-/-}$mice showed significant recovery of function by $7 \mathrm{~d}$ after bPyX compared to the functional nadir observed at day 2 after lesion (Fig. 3C,D, G,H), and 1 week earlier 
A


Figure 6. Bilateral pyramidotomy does not alter raphespinal terminal distribution. $\boldsymbol{A}, \mathrm{A}$ schematic shows the location of the NRM and the bilateral spinal innervation of the RPST. $\boldsymbol{B}$, Bar chart shows average density of $5 \mathrm{HT}+$ axons per $\mathrm{mm}^{2}( \pm \mathrm{SEM})$ in cervical spinal ventral horn in bPyX and sham-lesioned $n g r 1^{+/+}$and $n g r 1^{-1-}$ mice. $(-J$, Photomicrographs show 5-HT+ raphespinal axons terminating in the $(6 / \mathbf{C} 7$ spinal ventral horn contralateral $(\boldsymbol{C}-\boldsymbol{F})$ and ipsilateral $(\boldsymbol{G}-\boldsymbol{J})$ to a unilateral BDA injection into the red nucleus in $n g r 1^{+/+}(\boldsymbol{C}, \mathbf{G}, \boldsymbol{E}, \boldsymbol{I})$ and $n g r 1^{-/-}(\boldsymbol{D}, \boldsymbol{H}, \boldsymbol{F}, \boldsymbol{J})$ mice after sham $\left(\boldsymbol{C}, \boldsymbol{D}, \boldsymbol{G}, \boldsymbol{H} ; n=9\right.$ for $n g r 1^{+/+} ; n=$ 8 for $\left.n g r 1^{-/-}\right)$or bPyX $(\boldsymbol{E}, \boldsymbol{F}, I, J ; n=11$ per genotype). There was no significant difference in the density of 5 -HT + raphespinal axons in the ipsilateral $(\boldsymbol{G}-\boldsymbol{J})$ or contralateral $(\boldsymbol{C}-\boldsymbol{F})$ ventral horn between $n g r 1^{+/+}(\boldsymbol{C}, \boldsymbol{G}, \boldsymbol{E}, \boldsymbol{I})$ and $n g r 1^{-/-}$mice $(\boldsymbol{D}, \boldsymbol{H}, \boldsymbol{F}, \boldsymbol{J})$ after bPyX or sham lesion $(\boldsymbol{B})$. Scale bar, $500 \mu \mathrm{m}$.

compared with lesioned $n g r 1^{+/+}$mice. By $35 \mathrm{dpl}, n g r 1^{-/-}$mice had recovered to $50 \%$ of their baseline value, demonstrating that spontaneous recovery of function is enhanced in the sensitized $n g r 1^{-1-}$ background. These data are consistent with the hypothesis that the absence of ngr 1 elevates structural plasticity within remaining intact motor circuits to augment spontaneous functional recovery. Critically, grid-walking function provides the best correlate to explore plasticity-based mechanisms of functional restitution over a 1 month time frame of recovery.

\section{Plasticity of rubrospinal projections correlates with spontaneous functional recovery after bilateral pyramidotomy}

We sought to identify anatomical correlates of spontaneous functional recovery after complete CST lesion in adult mice. Previous data suggested that the rubrospinal tract (RST) has a parallel function to the CST (Kennedy and Humphrey, 1987; Kennedy, 1990; Raineteau and Schwab, 2001; Raineteau et al., 2001); therefore, we focused on projections from the red nucleus. We hypothesized that after complete CST lesion in the adult, plasticity within rubral projections could drive spontaneous recovery of function, and, furthermore, deleting NgR1 would augment plasticity and enhance functional recovery. We labeled rubral projections via a single stereotaxic microinjection of $100 \mathrm{nl}$ of BDA into the magnocellular region of the red nucleus unilaterally in adult $n g r 1^{+/+}$and $n g r 1^{-/-}$mice 4 weeks after bPyX or sham lesion (Fig. $4 A, B$ ). A single injection site was chosen to minimize tracer


spread into adjacent spinally projecting nuclei such as the interstitial nucleus of Cajal, periaqueductal gray, nucleus of Darkschewitsch, and mesencephalic reticular nucleus. Ten days after BDA injection, mice were perfused, and sections through the brainstem and cervical spinal cord were prepared for immunohistochemistry and densitometric analysis of BDA+ rubral axons.

We observed numerous BDA+ somata in the magnocellular region of the red nucleus and labeled fibers innervating multiple brainstem structures (Figs. 5 and Figs. 7) and the cervical spinal cord (Fig. 4). Close inspection of the cervical spinal cord revealed a tight bundle of BDA + axons in the dorsolateral funiculus (DLF) contralateral to the injection site (Fig. $4 E-$ $H)$. BDA+ RST axon terminals were observed exiting the DLF and densely innervating intermediate laminas V-VII of cervical spinal gray matter, with few terminals reaching the ventral horn (below lamina VII, shown schematically in Fig. $4 E)$ in sham-lesioned $n g r 1^{+/+}(E, C)$ and $n g r 1^{-/-}(F, C)$ mice. The density of RST terminals significantly increased in dorsal and ventral halves of the spinal cord in both $n g r 1^{+/+}$(Fig. 4, compare $E, G$ ) and $n g r 1^{-1-}$ (compare $\left.F, H\right)$ mice after bPyX $(C ; p<0.0005$, ANOVA). Furthermore, ngri ${ }^{-1-}$ mice had significantly more dense RST terminals throughout cervical gray matter after bPyX compared to lesioned $n g r 1^{+/+}$mice (Fig. $4 C$; $p<0.0005$, ANOVA). To determine efficiency of BDA labeling, we assessed the density of BDA+ axons in the caudal pontine reticular nucleus ( $\mathrm{PnC}$ ) immediately caudal to where the rubrospinal tract crosses the midline at the ventral tegmental decussation. There was no significant difference in the density of BDA+ axons in the PnC in $n g r 1^{+/+}$or $n g r 1^{-/-}$mice after bPyX or sham lesion (Fig. $4 D$ ). These data suggest that reorganization of the intact RST could be mediating spontaneous recovery of grid-walking function after bPyX in $n g r 1^{+/+}$mice, and, furthermore, the enhanced plasticity of RST terminals observed in $n g r 1^{-1-}$ could underlie the augmented behavioral recovery observed in $n g r 1^{-/-}$mice.

\section{Plasticity of rubropontine projections correlates with spontaneous functional recovery after bilateral pyramidotomy}

Previous studies have shown that the BPN receives increased innervation from the intact primary motor cortex after unilateral pyramidotomy (Thallmair et al., 1998; Z'Graggen et al., 1998, 2000; Raineteau et al., 1999) and may serve as an important relay station between motor cortex and the spinal cord in the absence of a functional CST. As the BPN is a crucial intercalation site between the cerebral cortex and cerebellum and is critical for controlling motor coordination, precision, and timing (Cicirata et al., 2005), we sought to determine whether the red nucleus innervates the pontine nuclei (rubropontine projection), and furthermore whether this innervation is altered after complete CST lesion. 
A survey of the pontine nuclei revealed a consistent but sparse pattern of BDA+ rubrofugal axons in the traced ipsilateral (Fig. 5G,H) and nontraced contralateral $(C, D)$ BPNs 2 weeks after unilateral injection of BDA into the right red nuclei of sham-lesioned $n g r 1^{+/+}(C, G)$ and $n g r 1^{-/-}(D, H)$ mice. The density of $\mathrm{BDA}+$ axons was not significantly different between genotypes (Fig. 5B), thus indicating normal wiring of this projection in intact $n g r 1^{-/-}$mice. We observed a significant increase in the density of $\mathrm{BDA}+$ rubropontine axons in the ipsilateral (Fig. $5 I, J)$ and contralateral $(E, F)$ BPNs in $n g r 1^{+/+}(E, I)$ and $n g r 1^{-/-}(F, J)$ mice 6 weeks after bPyX compared to sham-lesioned controls $(B ; p<0.0005$, ANOVA). Additionally bPyX-induced plasticity of the intact rubropontine projection was significantly increased in ngrl ${ }^{-/-}$compared to $n g r 1^{+/+}$mice (Fig. $5 B ; p<0.0005$, ANOVA). Therefore, in addition to enhanced innervation of the dorsal and ventral cervical spinal cord by the RST after bPyX, novel lesion-induced rubropontine connections could also mediate spontaneous recovery of function after partial SCI.

\section{Plasticity of rubro-raphe projections} correlates with spontaneous functional recovery after bilateral pyramidotomy In addition to identifying an enhanced lesion-induced rubropontine projection, BDA tracing also revealed a previously undescribed connection between the red nucleus and the NRM (see Fig. 7). The NRM is the originating locus of the raphespinal tract (RPST). The RPST is a serotonergic projection that descends the spinal cord in the DLF and terminates in all lamina at every spinal segment (Jones and Light, 1990; Hornung, 2003) and is known to have important roles in both nociception and in the initiation of locomotion (Kiehn, 2006). Therefore, we sought to determine whether this novel rubro-raphe projection was reinforced after complete CST lesion and was thereby capable of driving spontaneous recovery of function after partial SCI.

As an important first step to investigating a functional role for this novel rubro-raphe connection, we assessed whether wiring of the RSPT was altered after bPyX. As the RPST is predominantly a serotonergic projection (Dahlström and Fuxe, 1964; Bowker et al., 1983; Bowker and Abbott, 1990; Jones and Light, 1990), we can assess the density of its spinal gray matter terminals with immunohistochemistry to 5-HT. We observed diffuse 5-HT immunoreactivity (5-HT-IR) throughout the ipsilateral and contralateral (to BDA traced side) ventral horns in both $n g r 1^{+/+}$(Fig. $6 C, G)$ and $n g r 1^{-1-}(D, H)$ mice after sham lesion. There was no significant difference in the density of 5-HT-IR terminals between $n g r 1^{+/+}$and $n g r 1^{-/-}$mice after bPyX or sham lesion (Fig. $6 B)$. Therefore, owing to the lack of structural reorganization of the RPST after bPyX, its possible role in mediating spontaneous recovery of function after SCI must originate from novel inputs in part from the red nucleus.

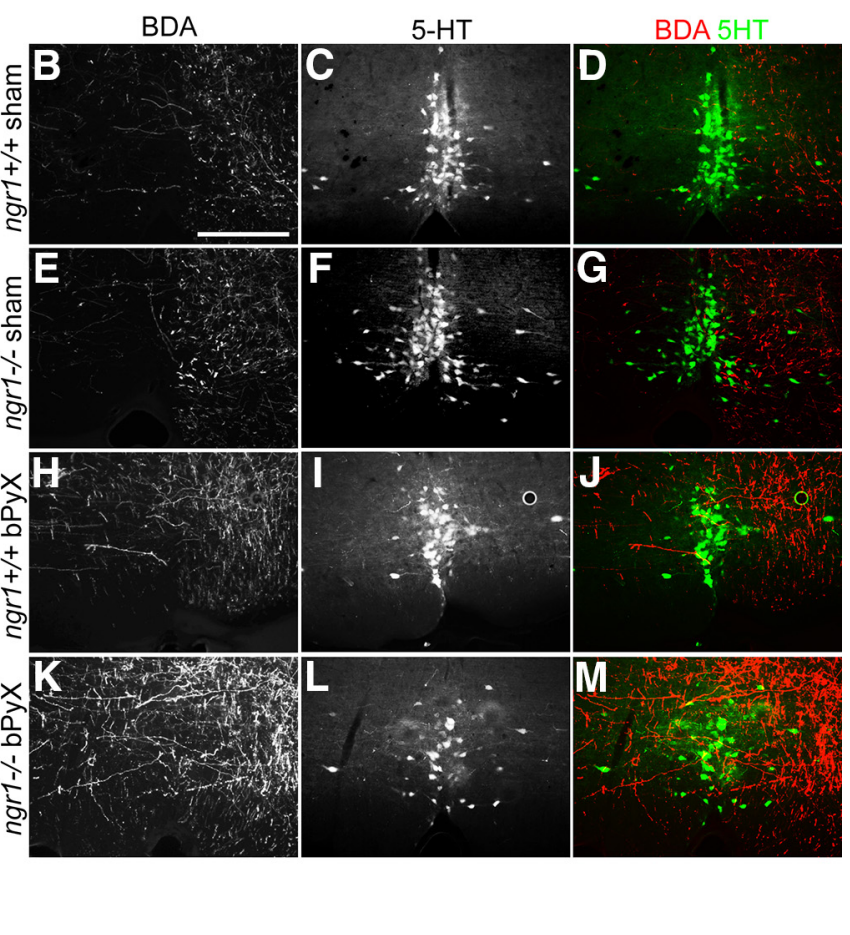

dotomy significantly increases rubrofugal innervation of the nucleus raphe magnus. $A, A$ schematic shows the relative location of the red nuclei and the NRM, the site of the unilateral BDA injection, and the location of the de novo rubro-raphe circuit (red stippled line). $\boldsymbol{B}-\boldsymbol{M}$, Photomicrographs show $\mathrm{BDA}+$ rubro-raphe axons $(\boldsymbol{B}, \boldsymbol{E}, \boldsymbol{H}, \boldsymbol{K})$ in close apposition to 5-HT+ NRM neurons $(\boldsymbol{C}, \boldsymbol{F}, \boldsymbol{I}, \boldsymbol{L})$ and overlay $(\boldsymbol{D}, \boldsymbol{G}, \boldsymbol{J}, \boldsymbol{M}$; red, BDA + axons; green, 5 -HT + NRM neurons) 6 weeks after bPyX (H-M; (esion ( $\boldsymbol{B}-\mathbf{G} ; n=9$ for $n g r 1^{++} ; n=8$ for $\left.n g r 1^{-/}\right)$in $n g r 1^{+/+}(\boldsymbol{B}-\boldsymbol{D}, \boldsymbol{H}-\boldsymbol{J})$ and $n g r 1^{-/}$ and $n g r 1^{-/-}$mice after sham lesion $(\boldsymbol{N}$; data are shown as the average density of BDA + axons per square millimeter \pm SEM; compare $\boldsymbol{D}, \boldsymbol{G})$. The density of BDA + rubro-raphe axons was significantly elevated in the NRM 6 weeks after bPyXin $n g r 1^{+/+}$and $n g r 1^{-/-}$mice compared to sham-lesioned $n g r 1^{+/+}$and $n g r 1^{-/-}$mice $\left(\boldsymbol{N} ;{ }^{\#} p<0.005\right.$, ANOVA; compare $\boldsymbol{D}, \mathbf{J}$; compare $\left.\mathbf{G}, \boldsymbol{M}\right)$. Lesion-induced enhanced plasticity of BDA + rubro-raphe axon terminals was significantly augmented in $n g r 1^{-/-}$compared to $n g r 1^{+/+}$mice in the NRM 6 weeks after bPyX $\left(\boldsymbol{N} ;{ }^{*} p<0.005\right.$, ANOVA; compare $\boldsymbol{E}, \boldsymbol{F}$; compare $\left.\mathbf{I}, \boldsymbol{J}\right)$. Scale bar, $100 \mu \mathrm{m}$.

Double immunofluorescent staining of sections through the NRM for serotonin and BDA showed close apposition of rubral axons with the cell bodies of 5-HT+ RPST neurons (Fig. 7B-M). There was no significant difference in the density of rubro-raphe terminals between $n g r 1^{+/+}$and $n g r 1^{-/-}$after sham lesion (Fig. $7 N$, compare $D, G)$. However, we observed a significant increase in the density of BDA + rubro-raphe terminals in both $n g r 1^{+/+}$ (Fig. 7H-J,N; $p<0.0005$, ANOVA) and $n g r 1^{-/-}(K-M, N ; p<$ 0.0005 , ANOVA) mice after bPyX compared to sham lesion. Furthermore, bPyX-induced plasticity of this novel connection was significantly increased in $n g r 1^{-/-}$compared to $n g r 1^{+/+}$mice (Fig. $7 N ; p<0.0005$, ANOVA). Therefore, increased innervation of the NRM by rubrofugal axons suggests that this novel pathway may also play an important role in mediating spontaneous recovery of function after partial SCI.

Pharmacogenetic silencing of the nucleus raphe magnus abrogates spontaneous functional recovery after complete corticospinal tract lesion

These data clearly establish three intact alternate motor projections that undergo significant structural reorganization after complete CST lesion that correlate with spontaneous functional recovery. We used a pharmacogenetic approach to determine whether these de novo circuits were driving functional restoration after bPyX. Targeting the red nucleus directly, either via surgical resection, chemical ablation, or pharmacogenetic silencing, 

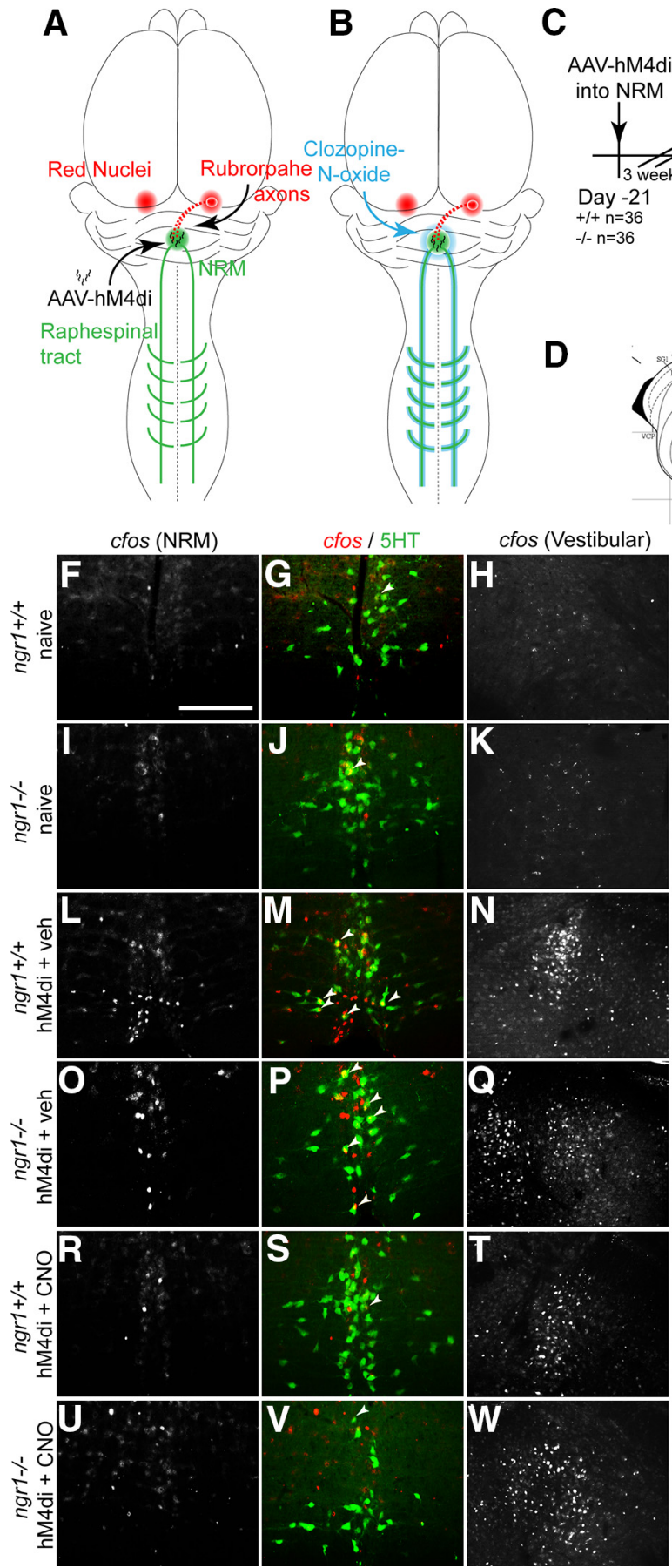

Figure 8. Activation of the inhibitory DREADD receptor hM4di abrogates activity-induced c-fos expression in NRM neurons. $\boldsymbol{A}$ $D, A$ schematic shows the relative location of the red nuclei, NRM, and rubro-raphe axons (red stippled line) and the location of AAV2-CAG-hSyn-hM4di-HA-IRES-mCitrine injection into the NRM $(\boldsymbol{A})$ and its relative location to the LVNs $(\boldsymbol{D})$. $\boldsymbol{B}$, Intraperitoneal injection of CNO activates hM4di and silences NRM-projecting raphespinal axons (outlined in blue). The time line for experiments described in Figures 8-10 is schematized in C. Ngr ${ }^{+/+}(n=36)$ and $n g r 1^{-1-}(n=36)$ mice received a single $75 \mathrm{nl}$ stereotaxic injection of high-titer $\left(1 \times 10^{13} \mathrm{pfu} / \mathrm{ml}\right)$ AAV-hM4di into the NRM. After 3 weeks, mice were split into two groups: a red group, to anatomically assess the expression of hM4di and the molecular activation status of NRM neurons expressing hM4di ( $n=12$ per genotype), and a blue group ( $n=24$ per genotype), to assess the functional impact of transiently silencing NRM neurons after bPyX or sham lesion. Unlesioned $n g r 1^{+/+}$and $n g r 1^{-/-}$mice in the red group underwent behavioral assessment using the grid-walking task on day 0 ( 3 weeks after AAV injection), 30 min after an intraperitoneal injection of either vehicle $(n=6$ per genotype) or CNO ( $n=6$ per genotype), and a second behavioral assessment $24 \mathrm{~h}$ later. $\boldsymbol{E}$, There was no significant difference in the percentage of missed steps made by naive $n g r 1^{+/+}$or $n g r 1^{-/-}$mice after CNO compared to the vehicle treatment or $24 \mathrm{~h}$ after drug washout. $\boldsymbol{F}-\boldsymbol{W}$, Photomicrographs show coronal sections of brainstem stained with antibodies to c-fos (white and red) and 5-HT (green; arrowheads denote colocalization). Few c-fos + nuclei were observed in the NRM or LVNs of naive $n g r 1^{+/+}$ $(\boldsymbol{F}-\boldsymbol{H})$ and $n g r 1^{-/-}(\boldsymbol{I}-\boldsymbol{K})$ mice. Significantly more c-fos + nuclei were observed in $5-\mathrm{HT}+$ neurons after 3 min of running on the rotarod in both $n g r 1^{+/+}(\boldsymbol{L}, \boldsymbol{M})$ and $n g r 1^{-/-}(\mathbf{O}, \boldsymbol{P})$ mice compared to naive controls $\left(\boldsymbol{X} ;{ }^{*} p<0.005\right.$, ANOVA). CNO treatment would not allow us to differentiate between its CST redundant functions and its capacity to form new circuits to drive compensatory function after the loss of the CST. Furthermore, targeting the BPNs would also fail to specifically assess the role of de novo rubral circuitry after bPyX because many afferent and efferent pathways including the rubropontine and corticopontine (which remains intact after $\mathrm{bPyX}$ ) projections converge on these relay nuclei (Cicirata et al., 2005). Therefore, we chose to transiently silence the novel rubroraphe projections in vivo via activation of the inhibitory DREADD (designer receptor exclusively activated by designer drugs) receptor hM4di. DREADDs are G-proteincoupled receptors that are activated or inhibited by the otherwise inert drug CNO (Rogan and Roth, 2011; Lee et al., 2014). Acute delivery of CNO to neurons expressing hM4di activates G-proteinassociated inwardly rectifying potassium channels, which leads to membrane hyperpolarization that ultimately induces silencing of the infected neurons. (Rogan and Roth, 2011).

To transiently silence rubro-raphe target neurons, we delivered a single $75 \mathrm{nl}$ injection of high-titer $\left(1 \times 10^{13} \mathrm{pfu} / \mathrm{ml}\right)$ AAV2-hSynHA-hM4di-IRES-mCitrine stereotaxically into the NRMs of $n g r 1^{+/+}$and $n g r 1^{-/-}$ mice (Fig. $8 A, C, D ; n=36$ per genotype). Three weeks after AAV injection, mice were split into two groups (Fig. $8 C$ ). The first group (Fig. $8 C$, red group; $n g r 1^{+/+}$, $\left.n=12 ; \operatorname{grl}^{-1-}, n=12\right)$ underwent two sessions of functional testing with gridwalking analysis before (intraperitoneal vehicle injection; Fig. $8 C$, split black arrow) and $30 \mathrm{~min}$ after (split blue arrow) intraperitoneal $\mathrm{CNO}$ injection to assess the impact of silencing the NRM on motor function in naive mice (Fig. $8 B$ ). The next day these mice underwent an additional behavioral testing session to assess

\section{$\leftarrow$}

significantly reduced the number of $c-$-os +5 -HT + NRM neurons in $n g r 1^{+/+}(\boldsymbol{R}, S)$ and $n g r 1^{-/-}(\boldsymbol{O}, \boldsymbol{P})$ mice compared to nave controls $\left(\boldsymbol{X} ;{ }^{*} p<0.005\right.$, ANOVA). Naive $n g r 1^{+/+}(\boldsymbol{H})$ and $\operatorname{grr}^{-1-}(\boldsymbol{K})$ mice that were not run on the rotarod showed little c-fos induction in the LVNs ( $)$. Significantly more $c$-fos + nuclei were observed in the LVNs in both $n g r 1^{+/+}(\boldsymbol{N})$ and $n g r 1^{-/-}(\boldsymbol{Q})$ mice 60 min after running on the rotarod $\left(Y ;{ }^{*} p<0.005\right.$, ANOVA). Delivery of CNO failed to significantly alter the number of c-fos + LVNs in either $n g r 1^{+/+}(T)$ or $n g r 1^{-/-}($W $)$mice compared to vehicletreated controls ( $($ ). Data are shown as the average percentage of missed steps during 3 min of grid walking $\pm \operatorname{SEM}(\boldsymbol{E})$, as the average of the percentage of $\mathrm{c}$-fos +5 -HT + neurons \pm SEM $(X)$, and the average number of $\mathrm{f}-$ fos + neurons in the LVNs \pm SEM ( $\eta$. Scale bars, $100 \mu \mathrm{m}$. 
the subacute impacts of CNO treatment. After behavioral assessment, mice received an additional intraperitoneal injection of either vehicle or CNO $(n=6$ per genotype), and $30 \mathrm{~min}$ later were run on the rotarod. Sixty minutes after running on the rotarod, mice were perfused for anatomical assessment of c-fos induction in the NRM. Previous studies have shown that acute experience on the rotarod stimulates robust induction of the immediate early gene c-fos in NRM neurons (Sluka and Rasmussen, 2010). Therefore, silencing these neurons via CNO-mediated activation of hM4di should abolish c-fos induction, thereby establishing a molecular signature of CNO-mediated hM4di activation. The second group (Fig. $8 C$, blue group; $n g r 1^{+/+}, n=24 ; n g r 1^{-/-}, n=24$ ) underwent identical functional testing before (vehicle injection; Fig. 8C, split black arrow) and after (split blue arrow) $\mathrm{CNO}$ delivery at baseline (day -5$)$ and on days $4,7,14,21,28$, and 35 after bPyX $(n=12$ per genotype) or sham lesion $(n=8$ per genotype), allowing us to determine the temporal impact of silencing the NRM throughout the testing period.

A single injection of AAV2-hSynhM4di-IRES-mCitrine into the NRM did not significantly elevate the percentage of missed steps made by either $n g r 1^{+/+}$or $n g r 1^{-/-}$naive mice during $3 \mathrm{~min}$ of grid walking $30 \mathrm{~min}$ after intraperitoneal injection of either vehicle or CNO (Fig. 8E). Twenty-four hours later, there was still no detectable effect of the drug on grid-walking competency (Fig. 8E). Therefore, transient silencing of the raphespinal tract does not influence skilled locomotor function in naive mice. The mCitrine signal marking hM4di expression was low level and inconsistently visualized by fluorescence microscopy due to the inefficiency of IRES-dependent reporter expression (Mizuguchi et al., 2000; Ngoi et al., 2004). Therefore, to confirm expression of hM4di and subsequent silencing of neurons expressing the receptor via $\mathrm{CNO}$ application, we delivered either CNO $(n=6$ per genotype) or vehicle ( $n=6$ per genotype) and ran these mice on the rotarod (Fig. $8 C$, red group). Sixty minutes after the rotarod, mice were perfused and prepared for immunohistochemical detection of c-fos.

To control for baseline levels of c-fos induction during normal cage activity, a cohort of naive mice ( $n=6$ per genotype) that did not receive AAV2-hSyn-HA-hM4di-IRES-mCitrine injections and were not run on the rotarod were included in our analysis. Naive $n g r 1^{+/+}$(Fig. 8F, G,X) and $n g r 1^{-/-}$mice $(I, J, X)$ showed very little c-fos induction in 5 -HT + NRM neurons. Significantly more c-fos $+5-\mathrm{HT}+\mathrm{NRM}$ neurons were observed in AAV2-hSyn-HA-hM4di-IRES-mCitrine-injected $n g r 1^{+/+}$(Fig. $8 L, M, X ; p<0.005$, ANOVA) and $n g r 1^{-/}-$mice (Fig. 8O, $P, X$; $p<0.005$, ANOVA) treated with vehicle $60 \mathrm{~min}$ after running on the rotarod compared to naive mice. Delivery of CNO $30 \mathrm{~min}$ before rotarod running significantly attenuated the number of c-fos + 5-HT + neurons in the NRMs of AAV2-hSyn-HA-hM4diIRES-mCitrine-injected $n g r 1^{+/+}$(Fig. $8 R, S, X ; p<0.005$, ANOVA) and $n g r 1^{-\prime-}$ mice (Fig. $8 U, V, X ; p<0.005$, ANOVA)

\section{B Forelimb Right}



D

Hind limb Right



..•...ngr1t/+ sham vehicle .....ngr1+/+ sham CNO .....ngr1-/- sham vehicle ....ngr1-/- sham CNO -...ngr1-/- sham vehicle .....ngr1-/- sham CNO

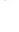

Figure 9. Activation of hM4di in the NRM fails to alter skilled locomotion after sham lesion. $A-D$, Skilled locomotion assessment of $n g r 1^{+/+}(n=10)$ and $n g r 1^{-/-}(n=10)$ mice using grid-walking analysis for 5 weeks starting 3 weeks after AAV-mediated transfection of the NRM with hM4di showed that the percentage of missed steps made by all four limbs was unaltered before or at anytime after sham lesion after treatment with vehicle or CNO. Error bars indicate SEM.

compared with vehicle-treated controls, suggesting that hM4di activation is silencing 5-HT+ NRM neurons. To ascertain the regional specificity of hM4di expression, we exploited the observation that $\mathrm{c}$-fos is robustly expressed in the lateral vestibular nuclei (LVN) complex after intense locomotion (Ruigrok et al., 1996). We did not observe substantial c-fos induction in naive $n g r 1^{+/+}$(Fig. $8 H$ ) or $n g r 1^{-/-}(K)$ mice. However, inspection of LVNs in the same tissue sections that were used to count c-fos + neurons in the NRM revealed significantly more $\mathrm{c}-$ fos + neurons in AAV2-hSyn-HA-hM4di-IRES-mCitrine-injected $n g r 1^{+/+}$ (Fig. $8 N, Y ; p<0.005$, ANOVA) and $n g r 1^{-/-}$mice (Fig. $8 Q, Y$; $p<0.005$, ANOVA) compared with naive controls. CNO treatment did not significantly alter the number of c-fos + LVN neurons in either $n g r 1^{+/+}$(Fig. 8T,Y;p<0.005, ANOVA) or $n g r 1^{-/-}$(Fig. $8 \mathrm{~W}, Y ; p<0.005$, ANOVA) AAV2-hSyn-HAhM4di-IRES-mCitrine-injected mice, thus confirming that stereotaxic injections of virus were confined to the NRM and did not spread to other adjacent regions within the brainstem (Fig. 8D). These data suggest that 3 weeks after AAV injection, hM4di is robustly expressed in the NRM, and its activation via acute delivery of CNO can manipulate the function of NRM neurons.

\section{Pharmacogenetic silencing of the nucleus raphe magnus abrogates spontaneous functional recovery after complete corticospinal tract lesion}

To assess whether silencing the de novo rubro-raphe circuit in vivo via targeting hM4di to the NRM influences spontaneous recovery of function after bPyX or sham lesion (Fig. $9 A-D$ ), we assessed the percentage of missed steps made during 3 min of grid walking by $n g r 1^{+/+}$mice before (Fig. $10 A, B, E, F$, black lines, 
A



C



E

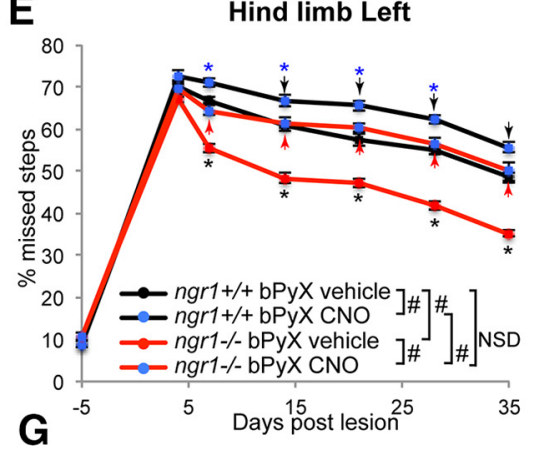

Left hindlimb

\begin{tabular}{|c|c|c|c|c|c|}
\hline $\mathrm{dpl}$ & 7 & 14 & 21 & 28 & 35 \\
\hline$n g r 1+/+b P y X$ & & & & & \\
\hline Veh treatment & NSD & * & * & * & * \\
\hline $\mathrm{CNO}$ treatment & NSD & NSD & * & * & * \\
\hline ngr1-/- bPyX & & & & & \\
\hline Veh treatment & * & * & * & * & * \\
\hline $\mathrm{CNO}$ treatment & NSD & NSD & * & * & * \\
\hline
\end{tabular}
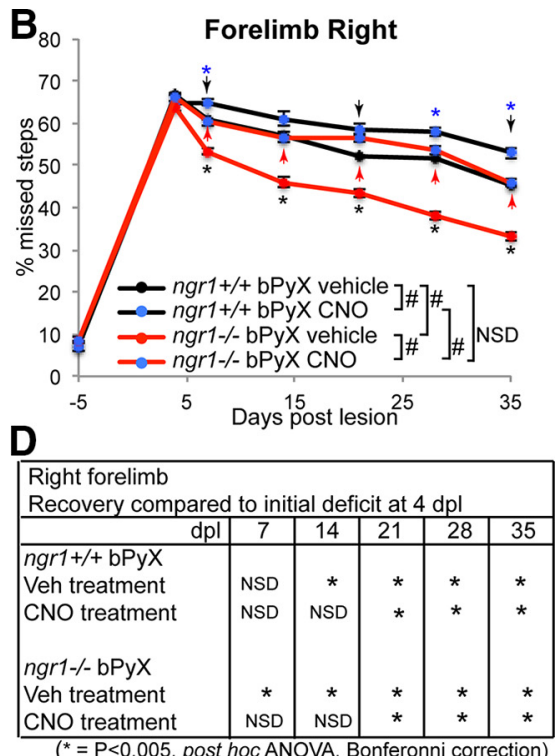

$\mathbf{F}$

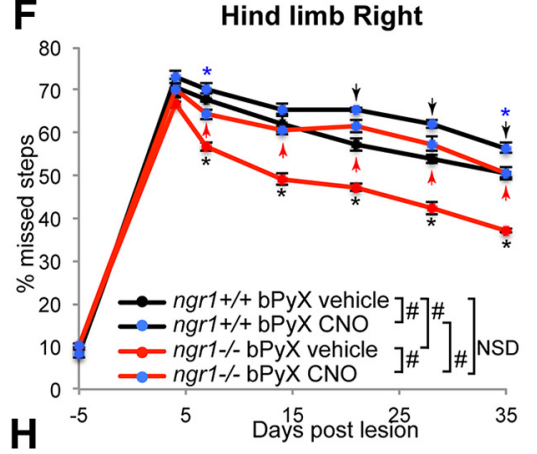

Right hindlimb

\begin{tabular}{|r|c|c|c|c|c|} 
Recovery compared to initial deficit at $4 \mathrm{dpl}$ \\
\hline $\mathrm{dpl}$ & 7 & 14 & 21 & 28 & 35 \\
\hline
\end{tabular}

\begin{tabular}{|l|c|c|c|c|c|}
\hline $\mathrm{dpl}$ & 7 & 14 & 21 & 28 & 35 \\
\hline ngr1+/+ bPyX & & & & & $*$ \\
Veh treatment & NSD & $*$ & $*$ & $*$ & $*$ \\
CNO treatment & NSD & NSD & $*$ & $*$ & $*$ \\
ngr1-/- bPyX & & & & & \\
Veh treatment & $*$ & $*$ & $*$ & $*$ & $*$ \\
CNO treatment & NSD & NSD & $*$ & $*$ & $*$ \\
\hline
\end{tabular}

${ }^{*}=\mathrm{P}<0.005$, post hoc ANOVA, Bonferonni correction $)$

Figure 10. Activation of hM4di in the NRM abrogates spontaneous recovery of skilled locomotor function after bilateral pyramidotomy. $\boldsymbol{A}-\boldsymbol{H}$, The effects of transiently silencing the NRM via activation of hM4di on skilled locomotion after bPyX was assessed by counting the number of footfalls made by forelimbs $(\boldsymbol{A}, \boldsymbol{B})$ and hindlimbs $(\boldsymbol{E}, \boldsymbol{F})$ during 3 min of grid walking on a $2.5 \times 2.5 \mathrm{~cm}$ mesh grid and analyzed using repeated-measures ANOVA with Bonferroni's correction for multiple comparisons $(A, B, E, F)$ with post hoc ANOVA $(\boldsymbol{A}-\boldsymbol{H})$. Data are shown as the average number of missed steps expressed as a percentage of total steps made over $3 \mathrm{~min} \pm$ SEM. As in (Fig. 3), both $n g r 1^{+/+}(n=14)$ and $n g r 1^{-/-}(n=14)$ mice made significantly more errors with their left forelimbs $\left({ }^{\#} F_{(3,29)}=1802.362, p<0.0005\right)$, right forelimbs $\left({ }^{\#} F_{(3,29)}=1960.634, p<0.0005\right)$, left hindlimbs $\left({ }^{\#} F_{(3,29)}=\right.$ $2202.006, p<0.0005)$, and right hindlimbs ( $\left.{ }^{\#} F_{(3,29)}=1959.227, p<0.0005\right)$ after bPyX compared to sham-lesioned control $n g r 1^{+/+}(n=10)$ and $n g r 1^{-/-}(n=10)$ mice (Fig. 9). Consistent with Figure $3, n g r 1^{+/+}$mice demonstrated significant spontaneous functional recovery in all four limbs by $14 \mathrm{dpl}$, and $n g r 1^{-/}$mice by $7 \mathrm{dpl}$, compared to maximum deficits at $4 \mathrm{dpl}$ $\left(\boldsymbol{C}, \mathbf{D}, \mathbf{G}, \boldsymbol{H} ;{ }^{*} p<0.005\right)$. Intraperitoneal CNO significantly attenuated spontaneous recovery made by both $n g r 1^{+/+}$and $n g r 1^{-1}$ mice in left forelimbs $\left(A ;{ }^{\#} F_{(3,32)}=62.569, p<0.0005\right)$, right forelimbs $\left(B ;{ }^{\#} F_{(3,32)}=65.452, p<0.0005\right)$, left hindlimbs $\left(\boldsymbol{E}_{;}{ }^{\#} F_{(3,32)}=104.047, p<0.0005\right)$, and right hindlimbs $\left(\boldsymbol{F}_{;}{ }^{\#} F_{(3,32)}=95.395, p<0.0005\right)$. For $n g r 1^{+/+}$mice, compare black lines and black dots for intraperitoneal vehicle with black lines and blue dots for intraperitoneal CNO (black arrow heads; post hoc ANOVA, $p<0.005$ ). For $n g r 1^{-/-}$mice, compare red lines and red dots for intraperitoneal vehicle with red lines and blue dots for intraperitoneal CNO (red arrow heads; posthoc ANOVA, $p<0.005$ ). Posthoc analyses showed that intraperitoneal CNO nullified spontaneous recovery observed in $n g r 1^{+/+}$mice up to $35 \mathrm{dpl}$ in the left forelimb $(\boldsymbol{C})$, and up to $21 \mathrm{dpl}$ in the right forelimb $(\boldsymbol{D})$ and left $(\boldsymbol{G})$ and right $(\boldsymbol{H})$ hindlimbs. Intraperitoneal $\mathbf{C N O}$ also nullified spontaneous recovery in $n g \mathrm{r}^{-1}{ }^{-}$mice up to $28 \mathrm{dpl}$ in the left forelimb $(\boldsymbol{C})$ and up to $21 \mathrm{dpl}$ in the right forelimb (D) and left $(\boldsymbol{G})$ and right $(\boldsymbol{H})$ hindlimbs. ${ }^{*} p<0.005$. Although CNO treatment abrogated spontaneous functional recovery in both genotypes, $n g r 1^{-/-}$mice recovered significantly better than $n g r 1^{+/+}$mice after bPyX after both vehicle $\left(A, B, E, F\right.$, black asterisk ${ }^{\#} p<0.0005$, post hoc ANOVA; ${ }^{*} p<0.005$, compare black lines and black spots with red lines and blue spots) and CNO $\left(\boldsymbol{A}, \boldsymbol{B}, \boldsymbol{E}, \boldsymbol{F}\right.$, blue asterisk; ${ }^{\#} p<0.05$, post hoc ANOVA; ${ }^{*} p<0.05$, compare black lines and blue spots with red lines and blue spots) treatment.

black dots) and after hM4di activation with $\mathrm{CNO}$ treatment (black lines, blue dots), and $n g r 1^{-/-}$mice before (red lines, red dots) and after CNO treatment (red lines, blue dots). As expected, expression of hM4di failed to alter the number of missed steps made by forelimbs (Fig. $9 A, B)$ or hindlimbs $(C, D)$ in $n g r 1^{+/+}$ mice before $(A-D$, stippled black lines, black dots) or after (stippled black lines, blue dots) $\mathrm{CNO}$ treatment, or in $n g r 1^{-/-}$ mice before $(A-D$, stippled red lines, red dots) or after (stippled red lines, blue dots) CNO treatment after sham lesion, thus confirming our previous data (Fig. 8) showing that activity in NRM neurons does not influence skilled locomotion in intact adult mice.

In line with our previous observations (Fig. 3), lesioned $\mathrm{ngrl}^{+/+}$mice treated with vehicle showed significant functional impairments in all four limbs after bPyX throughout the testing period ( $p<0.005$, ANOVA), but also showed significant spontaneous functional recovery by $14 \mathrm{~d}$ after lesion (Fig. 10C, D, G,H; $p<0.005$, ANOVA). Delivery of CNO to $n g r 1^{+/+}$ mice 30 min before their second gridwalking testing session resulted in a significant attenuation of spontaneous recovery of function in all four limbs compared to the vehicle treatment (Fig. 10A,B,E,F, black lines, blue dots; $p<0.005$, repeatedmeasures ANOVA). Post hoc analysis revealed that $\mathrm{CNO}$ treatment nullified spontaneous recovery of function back to day 4 after bPyX levels (nadir of measured functional deficits) up to $35 \mathrm{dpl}$ in the left forelimbs (Fig. 10C; $p<0.005$, ANOVA) and $21 \mathrm{dpl}$ in the right forelimbs $(D)$, left hindlimbs $(G)$, and right hindlimbs $(H)$. These data suggest that de novo rubro-raphe circuit-mediated activation of the NRM after bPyX is responsible for driving the majority of spontaneous recovery of function observed in wild-type mice after complete CST lesion.

Similarly, ngr1 ${ }^{-\prime-}$ mice treated with vehicle showed significant functional deficits throughout the testing period in all four limbs after bPyX $(p<0.005$, ANOVA), and also spontaneous functional recovery by $7 \mathrm{dpl}$ (Fig. 10C, D, G,H; $p<0.005$, ANOVA). As we observed in our previous cohort (Fig. 3), ngrl ${ }^{-/-}$ mice recovered significantly more function compared with $\mathrm{ngrl}^{+/+}$mice (Fig. 10A,B,E,F; $p<0.0005$, repeatedmeasures ANOVA). Delivery of CNO to $n g r 1^{-1-}$ mice 30 min before their second grid-walking testing session resulted in a significant attenuation of spontaneous recovery of function (Fig. 10A,B,E,F, red 
lines, blue dots; $p<0.005$, repeatedmeasures ANOVA). Post hoc analysis revealed that $\mathrm{CNO}$ treatment nullified spontaneous recovery of function back to day 4 after bPyX levels (nadir of measured deficits) up to $28 \mathrm{dpl}$ in the left forelimbs (Fig. 10C) and $21 \mathrm{dpl}$ in the right forelimbs $(D)$, left hindlimbs $(G)$, and right hindlimbs $(H)$. Additionally, there was no significant difference between $n g r 1^{+/+}$ mice treated with vehicle and $n g r 1^{-1-}$ mice treated with CNO (Fig. 10A, B,E,F, compare black lines, black dots and red lines, blue dots). These data suggest that novel rubro-raphe input into the NRM is partially responsible for driving spontaneous functional recovery after bPyX in plasticity-sensitized $n_{\mathrm{grl}} \mathrm{I}^{-/-}$mice. In contrast to $n g r 1^{+/+}$mice treated with $\mathrm{CNO}, \mathrm{grl}^{-1-}$ mice did not return to acute postinjury deficits levels after $\mathrm{CNO}$ treatment, suggesting that additional loci are contributing to functional recovery in this plasticity-sensitized background. Indeed elevated levels of structural plasticity observed in rubrospinal (Fig. 4) and rubropontine (Fig. 5) circuits in $n g r 1^{-1-}$ mice after bPyX could contribute to enhance spontaneous functional recovery.

\section{Discussion}

We sought to identify the mechanisms driving spontaneous functional recovery after partial SCI and determine whether they can be exploited to augment functional restoration. By ablating the CST in adult mice and using a combination of behavioral testing, anterograde tract tracing, and in vivo pharmacogenetic silencing, we can draw several conclusions. First, skilled locomotion analysis reveals spontaneous yet incomplete functional recovery after bPyX, thus validating this approach to dissecting the mechanisms driving spontaneous functional recovery after partial SCI. Second, structural plasticity of rubral projections to the BPNs, spinal cord, and NRM correlate with spontaneous recovery of skilled function. Third, enhancing structural plasticity within these lesion-induced connections by deleting $\mathrm{NgR} 1$ significantly augments spontaneous functional recovery. Finally, novel rubral connections are crucial in driving spontaneous recovery of function after bPyX (summarized in Fig. 11 ), as their transient inactivation significantly blunts functional recovery.

\section{Compensation and redundancy between descending motor pathways}

The limited capacity of adult CNS axons to regenerate after injury suggests that spontaneous recovery of function after $\mathrm{SCI}$ is driven by two nonexclusive mechanisms that rely on intact motor circuits. First, localized plasticity of intact terminals could unmask or strengthen prewired silent synapses. Second, widespread sprouting of intact fibers may connect targets that have lost afferent input to maintain or restore motor function. These mechanisms can be partially differentiated temporally, as redundant connections would restore function to prelesion levels acutely after injury, whereas structural changes would restore function over a protracted period of time. We used qualitatively different behavioral tasks to identify these two phases and focused on met- rics to dissect the mechanisms that drive compensatory spontaneous recovery rather than redundancy.

In line with a previous report (Kanagal and Muir, 2009), we failed to detect an effect of bPyX on overground locomotion. These data are also in agreement with reports that studied the effect of uPyX on overground locomotion that concluded that the CST has little or no role in driving this behavior in rodents. However, lesions to the rubrospinal, reticulospinal, DLF, and dorsal column projections all significantly impair overground locomotion (Muir et al., 2007). Therefore, studying axon regeneration within these pathways, all of which are axotomized after dorsal hemisection, would seem more appropriate than correlating CST axon regeneration with open-field locomotor recovery after experimental SCI.

Both $n g r 1^{+/+}$and $n g r 1^{-/-}$mice showed only a transient motor impairment in the tape removal task after bPyX, consistent with a previous study assessing the effect of unilateral PyX (Starkey et al., 2005). This was surprising, as we anticipated a more severe functional deficit in our study, as a bilateral lesion would remove the possibility of compensatory sprouting from the intact CST. However, minimal sprouting of intact CST axons in adult wild-type mice after uPyX (Cafferty et al., 2007) suggests that complete recovery in this task is dependent upon a non-CSTdriven mechanism. Similar to tape removal, both $n g r 1^{+/+}$and $n g r 1^{-1-}$ mice displayed significant functional impairments in grid-walking competency after bPyX. Although neither genotype recovered to prelesion baseline levels, $n g r 1^{-{ }^{-}}$mice recovered significantly more function compared to $\mathrm{ngrl}^{+/+}$mice after injury. Therefore, this behavioral task appeared sensitive enough to dissect the anatomical substrates driving spontaneous recovery of function after destruction of the CST.

\section{Structural plasticity of intact rubral projections correlates with spontaneous recovery of function}

The RST has been implicated previously in compensating for damage to the CST. First, the RST develops functional connections with brainstem premotor nuclei and spinal motor neurons before the CST does and is therefore capable of driving rudimentary motor skills during an epoch devoid of a functional CST 
(Williams et al., 2014). Second, lesions to the red nucleus (Whishaw et al., 1998) or spinal axotomy of the RST (Muir et al., 2007) result in deficits similar to those from uPyX. Third, sprouting of corticofugal axons into the red nucleus functionally reconnects the cortex to the periphery after uPyX (Z'Graggen et al., 1998). Fourth, sprouting of the RST into the spinal ventral horn drives EMG responses in forelimb muscles that have been deafferented after bPyX (Raineteau et al., 2001). Finally, the red nucleus projects somatotopically organized axons to all levels of the spinal cord (Murray and Gurule, 1979; Liang et al., 2012) and is therefore primed to execute voluntary motor commands. We observed sprouting of axons from the red nucleus into the BPNs, spinal ventral horn, and NRM in $n g r 1^{+/+}$mice after bPyX, which correlated with spontaneous functional recovery in grid walking. Enhancing plasticity within these projections by deleting NgR1 significantly augmented rubral axon sprouting and crucially boosted functional recovery after bPyX, suggesting that rubral pathways are fundamental in driving recovery of function after partial SCI.

\section{Silencing of the NRM reveals the central role of rubral projections in driving spontaneous functional recovery}

Pharmacogenetic silencing strategies have been successfully used to dissect the function of intact brainstem circuits (Esposito et al., 2014) and spinal circuits after stroke (Wahl et al., 2014). Therefore, we selected this approach to dissect the functional impact of the bPyX-induced de novo rubro-raphe circuit. Scant evidence for the existence and function of this circuit exists in the literature. A singular study showed that an excitatory circuit from the red nucleus to the NRM exists in the cat, and it was hypothesized to serve a modulatory motor function (West et al., 1982).

The NRM is part of the serotonergic raphe complex, which, together with the raphe pallidus and obscurus, forms the RPST that innervates all spinal lamina and segments (Liang et al., 2012). Although RPST axons mostly regulate nociceptive and motor function (Hornung, 2003; Kiehn, 2006), regeneration of this pathway has been shown to be crucial in mediating functional recovery after dorsal hemisection in $n g r 1^{-/-}$mice (Kim et al., 2004) and after pharmacological inhibition of NgR1 (Wang et al., 2006) and NogoA (Müllner et al., 2008). Therefore, activation of the RPST via bPyX-induced rubral innervation of the NRM could mediate functional recovery. We were unable to consistently detect expression of the HA or mCitrine tags 3 weeks after AAV injection in to the NRM. Therefore, we sought a molecular signature of hM4di status that would confirm its expression and subsequent inactivation. We exploited the observation that c-fos is robustly expressed in the NRM after rotarod running (Sluka and Rasmussen, 2010). Intact $n g r 1^{+/+}$and $n g r 1^{-/-}$mice demonstrated significant c-fos expression in the NRM 60 min after rotarod running, although $\mathrm{CNO}$ delivery $30 \mathrm{~min}$ before the rotarod significantly abrogated c-fos activation, thereby confirming expression and activation of hM4di.

Silencing the NRM had no effect on grid walking in intact $n g r 1^{+/+}$and $n g r 1^{-/-}$mice and is therefore not responsible for voluntary skilled movement in the intact CNS. In contrast, by 7 dpl, both $n g r 1^{+/+}$and $n g r 1^{-/-}$mice showed an abrogation of spontaneous recovery of skilled locomotor function after $\mathrm{CNO}$ delivery. This suggests that the RPST has acquired the capacity to drive skilled movements after bPyX. The half-life of CNO is less than $2 \mathrm{~h}$, thus allowing us to probe the function of the rubroraphe-raphespinal circuit repeatedly without permanently affecting its function. This allowed us a unique temporal insight into the circuitry that drives the emergence of spontaneous recovery of function after bPyX. Both $n g r 1^{+/+}$and $n g r 1^{-/-}$mice showed complete abrogation of spontaneous functional recovery during the first week after bPyX, suggesting that the rubro-raphe circuit is responsible for the majority of spontaneous recovery acutely after lesion. After $7 \mathrm{dpl}$, delivery of CNO impaired behavioral recovery of all four limbs in both $n g r 1^{+/+}$and $n g r 1^{-/-}$mice by $>50 \%$ throughout the rest of the testing period. These data suggest that the rubroraphe-raphespinal circuit plays a critical role in maintaining function after bPyX; however, additional circuits are recruited at later time points. These may include the reinforced rubropontine and rubrospinal circuits that we observed 6 weeks after bPyX, and also cortical input into the red nucleus, which has been shown to be elevated after CST lesion (Raineteau et al., 2001).

\section{Enhancing structural plasticity of intact projections augments functional recovery}

Evidence from previous studies supports targeting the Nogo$\mathrm{NgR}$ axis, as functional recovery mediated via sprouting of the intact CST can be elicited by UPyX at P2, before spinal axon myelination and NogoA deposition (Z'Graggen et al., 2000). Furthermore, stimulating sprouting of the intact CST after uPyX in the adult by antagonizing NogoA (Z'Graggen et al., 1998; Cafferty and Strittmatter, 2006) and NgR1 (Cafferty and Strittmatter, 2006) restores skilled forelimb function within 5 weeks of injury. Recently, decreased collateral sprouting of intact spinal axons and decreased functional recovery were observed after lateral hemisection in Wallerian degeneration delayed $\left(W L d^{s}\right)$ mutant mice (Collyer et al., 2014). These data suggest that the continued presence of NogoA-expressing oligodendrocytes in areas undergoing delayed degeneration (Dong et al., 2003) prevents the formation of collateral axons from intact projections that drive functional recovery. Additionally, elevating plasticity of intact CST axons after uPyX by digesting CSPGs with chondroitinase $\mathrm{ABC}$ also enhances collateral sprouting and functional recovery (Starkey et al., 2012). Together, these studies highlight the potency of targeting plasticity within remaining intact spinal and supraspinal circuits to restore function after partial SCI.

\section{References}

Atwal JK, Pinkston-Gosse J, Syken J, Stawicki S, Wu Y, Shatz C, TessierLavigne M (2008) PirB is a functional receptor for myelin inhibitors of axonal regeneration. Science 322:967-970. CrossRef Medline

Bareyre FM, Kerschensteiner M, Raineteau O, Mettenleiter TC, Weinmann O, Schwab ME (2004) The injured spinal cord spontaneously forms a new intraspinal circuit in adult rats. Nat Neurosci 7:269-277. CrossRef Medline

Bartus K, James ND, Didangelos A, Bosch KD, Verhaagen J, Yáñez-Muñoz RJ, Rogers JH, Schneider BL, Muir EM, Bradbury EJ (2014) Large-scale chondroitin sulfate proteoglycan digestion with chondroitinase gene therapy leads to reduced pathology and modulates macrophage phenotype following spinal cord contusion injury. J Neurosci 34:4822-4836. CrossRef Medline

Blackmore MG, Wang Z, Lerch JK, Motti D, Zhang YP, Shields CB, Lee JK, Goldberg JL, Lemmon VP, Bixby JL (2012) Kruppel-like Factor 7 engineered for transcriptional activation promotes axon regeneration in the adult corticospinal tract. Proc Natl Acad Sci US A 109:7517-7522. CrossRef Medline

Bowker RM, Abbott LC (1990) Quantitative re-evaluation of descending serotonergic and non-serotonergic projections from the medulla of the rodent: evidence for extensive co-existence of serotonin and peptides in the same spinally projecting neurons, but not from the nucleus raphe magnus. Brain Res 512:15-25. CrossRef Medline

Bowker RM, Westlund KN, Sullivan MC, Wilber JF, Coulter JD (1983) Descending serotonergic, peptidergic and cholinergic pathways from the raphe nuclei: a multiple transmitter complex. Brain Res 288:33-48. CrossRef Medline 
Bradbury EJ, Moon LD, Popat RJ, King VR, Bennett GS, Patel PN, Fawcett JW, McMahon SB (2002) Chondroitinase ABC promotes functional recovery after spinal cord injury. Nature 416:636-640. CrossRef Medline

Cafferty WB, Strittmatter SM (2006) The Nogo-Nogo receptor pathway limits a spectrum of adult CNS axonal growth. J Neurosci 26:1224212250. CrossRef Medline

Cafferty WB, Yang SH, Duffy PJ, Li S, Strittmatter SM (2007) Functional axonal regeneration through astrocytic scar genetically modified to digest chondroitin sulfate proteoglycans. J Neurosci 27:2176-2185. CrossRef Medline

Cafferty WB, Duffy P, Huebner E, Strittmatter SM (2010) MAG and OMgp synergize with Nogo-A to restrict axonal growth and neurological recovery after spinal cord trauma. J Neurosci 30:6825-6837. CrossRef Medline

Cicirata F, Serapide MF, Parenti R, Pantò MR, Zappalà A, Nicotra A, Cicero D (2005) The basilar pontine nuclei and the nucleus reticularis tegmenti pontis subserve distinct cerebrocerebellar pathways. Prog Brain Res 148: 259-282. CrossRef Medline

Collyer E, Catenaccio A, Lemaitre D, Diaz P, Valenzuela V, Bronfman F, Court FA (2014) Sprouting of axonal collaterals after spinal cord injury is prevented by delayed axonal degeneration. Exp Neurol 261:451-461. CrossRef

Courtine G, Song B, Roy RR, Zhong H, Herrmann JE, Ao Y, Qi J, Edgerton VR, Sofroniew MV (2008) Recovery of supraspinal control of stepping via indirect propriospinal relay connections after spinal cord injury. Nat Med 14:69-74. CrossRef Medline

Courtine G, Gerasimenko Y, van den Brand R, Yew A, Musienko P, Zhong H, Song B, Ao Y, Ichiyama RM, Lavrov I, Roy RR, Sofroniew MV, Edgerton VR (2009) Transformation of nonfunctional spinal circuits into functional states after the loss of brain input. Nat Neurosci 12:1333-1342. CrossRef Medline

Dahlström A, Fuxe K (1964) Localization of monoamines in the lower brain stem. Experientia 20:398-399. CrossRef Medline

Dickendesher TL, Baldwin KT, Mironova YA, Koriyama Y, Raiker SJ, Askew KL, Wood A, Geoffroy CG, Zheng B, Liepmann CD, Katagiri Y, Benowitz LI, Geller HM, Giger RJ (2012) NgR1 and NgR3 are receptors for chondroitin sulfate proteoglycans. Nat Neurosci 15:703-712. CrossRef Medline

Dong H, Fazzaro A, Xiang C, Korsmeyer SJ, Jacquin MF, McDonald JW (2003) Enhanced oligodendrocyte survival after spinal cord injury in Bax-deficient mice and mice with delayed Wallerian degeneration. J Neurosci 23:8682-8691. Medline

Duffy P, Wang X, Seigel CS, Tu N, Henkemeyer M, Cafferty WB, Strittmatter SM (2012) Myelin-derived ephrinB3 restricts axonal regeneration and recovery after adult CNS injury. Proc Natl Acad Sci U S A 109:5063-5068. CrossRef Medline

Esposito MS, Capelli P, Arber S (2014) Brainstem nucleus MdV mediates skilled forelimb motor tasks. Nature 508:351-356. CrossRef Medline

Festing MF, Altman DG (2002) Guidelines for the design and statistical analysis of experiments using laboratory animals. ILAR J 43:244-258. CrossRef Medline

Fournier AE, GrandPre T, Strittmatter SM (2001) Identification of a receptor mediating Nogo-66 inhibition of axonal regeneration. Nature 409: 341-346. CrossRef Medline

Fry EJ, Chagnon MJ, López-Vales R, Tremblay ML, David S (2010) Corticospinal tract regeneration after spinal cord injury in receptor protein tyrosine phosphatase sigma deficient mice. Glia 58:423-433. Medline

GrandPré T, Li S, Strittmatter SM (2002) Nogo-66 receptor antagonist peptide promotes axonal regeneration. Nature 417:547-551. CrossRef Medline

Hornung JP (2003) The human raphe nuclei and the serotonergic system. J Chem Neuroanat 26:331-343. CrossRef

Jones SL, Light AR (1990) Termination patterns of serotoninergic medullary raphespinal fibers in the rat lumbar spinal cord: an anterograde immunohistochemical study. J Comp Neurol 297:267-282. CrossRef Medline

Kanagal SG, Muir GD (2009) Task-dependent compensation after pyramidal tract and dorsolateral spinal lesions in rats. Exp Neurol 216:193-206. CrossRef Medline

Kennedy PR (1990) Corticospinal, rubrospinal and rubro-olivary projections: a unifying hypothesis. Trends Neurosci 13:474-479. CrossRef Medline

Kennedy PR, Humphrey DR (1987) The compensatory role of the parvocel- lular division of the red nucleus in operantly conditioned rats. Neurosci Res 5:39-62. CrossRef Medline

Kiehn O (2006) Locomotor circuits in the mammalian spinal cord. Annu Rev Neurosci 29:279-306. CrossRef Medline

Kim JE, Liu BP, Park JH, Strittmatter SM (2004) Nogo-66 receptor prevents raphespinal and rubrospinal axon regeneration and limits functional recovery from spinal cord injury. Neuron 44:439-451. CrossRef Medline

Lee HM, Giguere PM, Roth BL (2014) DREADDs: novel tools for drug discovery and development. Drug discovery today 19:469-473. CrossRef Medline

Liang H, Paxinos G, Watson C (2012) The red nucleus and the rubrospinal projection in the mouse. Brain Struct Funct 217:221-232. CrossRef Medline

Li W, Walus L, Rabacchi SA, Jirik A, Chang E, Schauer J, Zheng BH, Benedetti NJ, Liu BP, Choi E, Worley D, Silvian L, Mo W, Mullen C, Yang W, Strittmatter SM, Sah DW, Pepinsky B, Lee DH (2004) A neutralizing anti-Nogo66 receptor monoclonal antibody reverses inhibition of neurite outgrowth by central nervous system myelin. J Biol Chem 279:43780 43788. CrossRef Medline

Liu BP, Fournier A, GrandPré T, Strittmatter SM (2002) Myelin-associated glycoprotein as a functional ligand for the Nogo-66 receptor [comment]. Science 297:1190-1193. CrossRef Medline

Liu K, Lu Y, Lee JK, Samara R, Willenberg R, Sears-Kraxberger I, Tedeschi A Park KK, Jin D, Cai B, Xu B, Connolly L, Steward O, Zheng B, He Z (2010) PTEN deletion enhances the regenerative ability of adult corticospinal neurons. Nat Neurosci 13:1075-1081. CrossRef Medline

Liu K, Tedeschi A, Park KK, He Z (2011) Neuronal intrinsic mechanisms of axon regeneration. Annu Rev Neurosci 34:131-152. CrossRef Medline

Metz GA, Dietz V, Schwab ME, van de Meent H (1998) The effects of unilateral pyramidal tract section on hindlimb motor performance in the rat. Behav Brain Res 96:37-46. CrossRef Medline

Mizuguchi H, Xu Z, Ishii-Watabe A, Uchida E, Hayakawa T (2000) IRESdependent second gene expression is significantly lower than cap-dependent first gene expression in a bicistronic vector. Mol Ther 1:376-382. CrossRef

Moore DL, Blackmore MG, Hu Y, Kaestner KH, Bixby JL, Lemmon VP, Goldberg JL (2009) KLF family members regulate intrinsic axon regeneration ability. Science 326:298-301. CrossRef Medline

Muir GD, Whishaw IQ (1999) Complete locomotor recovery following corticospinal tract lesions: measurement of ground reaction forces during overground locomotion in rats. Behav Brain Res 103:45-53. CrossRef Medline

Muir GD, Webb AA, Kanagal S, Taylor L (2007) Dorsolateral cervical spinal injury differentially affects forelimb and hindlimb action in rats. Eur J Neurosci 25:1501-1510. CrossRef Medline

Müllner A, Gonzenbach RR, Weinmann O, Schnell L, Liebscher T, Schwab ME (2008) Lamina-specific restoration of serotonergic projections after Nogo-A antibody treatment of spinal cord injury in rats. Eur J Neurosci 27:326-333. CrossRef Medline

Murray HM, Gurule ME (1979) Origin of the rubrospinal tract of the rat. Neurosci Lett 14:19-23. CrossRef Medline

Ngoi SM, Chien AC, Lee CG (2004) Exploiting internal ribosome entry sites in gene therapy vector design. Curr Gene Ther 4:15-31. CrossRef Medline

Park KK, Liu K, Hu Y, Smith PD, Wang C, Cai B, Xu B, Connolly L, Kramvis I, Sahin M, He Z (2008) Promoting axon regeneration in the adult CNS by modulation of the PTEN/mTOR pathway. Science 322:963-966. CrossRef Medline

Paxinos G, Franklin KB (2001) The mouse brain in stereotaxic coordinates, 2nd edition. San Diego: Academic.

Raineteau O, Schwab ME (2001) Plasticity of motor systems after incomplete spinal cord injury. Nat Rev Neurosci 2:263-273. CrossRef Medline

Raineteau O, Z'Graggen WJ, Thallmair M, Schwab ME (1999) Sprouting and regeneration after pyramidotomy and blockade of the myelinassociated neurite growth inhibitors NI 35/250 in adult rats. Eur J Neurosci 11:1486-1490. CrossRef Medline

Raineteau O, Fouad K, Noth P, Thallmair M, Schwab ME (2001) Functional switch between motor tracts in the presence of the mAb IN-1 in the adult rat. Proc Natl Acad Sci U S A 98:6929-6934. CrossRef Medline

Rogan SC, Roth BL (2011) Remote control of neuronal signaling. Pharmacol Rev 63:291-315. CrossRef Medline

Ruigrok TJ, van der Burg H, Sabel-Goedknegt E (1996) Locomotion coincides with c-Fos expression in related areas of inferior olive and cerebellar nuclei in the rat. Neurosci Lett 214:119-122. CrossRef Medline 
Schnell L, Schwab ME (1990) Axonal regeneration in the rat spinal cord produced by an antibody against myelin-associated neurite growth inhibitors. Nature 343:269-272. CrossRef Medline

Shen Y, Tenney AP, Busch SA, Horn KP, Cuascut FX, Liu K, He Z, Silver J, Flanagan JG (2009) PTPsigma is a receptor for chondroitin sulfate proteoglycan, an inhibitor of neural regeneration. Science 326:592-596. CrossRef Medline

Sluka KA, Rasmussen LA (2010) Fatiguing exercise enhances hyperalgesia to muscle inflammation. Pain 148:188-197. CrossRef Medline

Starkey ML, Barritt AW, Yip PK, Davies M, Hamers FP, McMahon SB, Bradbury EJ (2005) Assessing behavioural function following a pyramidotomy lesion of the corticospinal tract in adult mice. Exp Neurol 195:524-539. CrossRef Medline

Starkey ML, Bartus K, Barritt AW, Bradbury EJ (2012) Chondroitinase ABC promotes compensatory sprouting of the intact corticospinal tract and recovery of forelimb function following unilateral pyramidotomy in adult mice. Eur J Neurosci 36:3665-3678. CrossRef Medline

Thallmair M, Metz GA, Z'Graggen WJ, Raineteau O, Kartje GL, Schwab ME (1998) Neurite growth inhibitors restrict plasticity and functional recovery following corticospinal tract lesions. Nat Neurosci 1:124-131. CrossRef Medline

Ueno M, Hayano Y, Nakagawa H, Yamashita T (2012) Intraspinal rewiring of the corticospinal tract requires target-derived brain-derived neurotrophic factor and compensates lost function after brain injury. Brain 135:1253-1267. CrossRef Medline

van den Brand R, Heutschi J, Barraud Q, DiGiovanna J, Bartholdi K, Huerlimann M, Friedli L, Vollenweider I, Moraud EM, Duis S, Dominici N, Micera S, Musienko P, Courtine G (2012) Restoring voluntary control of locomotion after paralyzing spinal cord injury. Science 336:1182-1185. CrossRef Medline

Venkatesh K, Chivatakarn O, Lee H, Joshi PS, Kantor DB, Newman BA, Mage R, Rader C, Giger RJ (2005) The Nogo-66 receptor homolog NgR2 is a sialic acid-dependent receptor selective for myelin-associated glycoprotein. J Neurosci 25:808-822. CrossRef Medline
Wahl AS, Omlor W, Rubio JC, Chen JL, Zheng H, Schröter A, Gullo M, Weinmann O, Kobayashi K, Helmchen F, Ommer B, Schwab ME (2014) Neuronal repair. Asynchronous therapy restores motor control by rewiring of the rat corticospinal tract after stroke. Science 344:1250-1255. CrossRef Medline

Wang X, Baughman KW, Basso DM, Strittmatter SM (2006) Delayed Nogo receptor therapy improves recovery from spinal cord contusion. Ann Neurol 60:540-549. CrossRef Medline

Wang X, Duffy P, McGee AW, Hasan O, Gould G, Tu N, Harel NY, Huang Y, Carson RE, Weinzimmer D, Ropchan J, Benowitz LI, Cafferty WB, Strittmatter SM (2011) Recovery from chronic spinal cord contusion after Nogo receptor intervention. Ann Neurol 70:805-821. CrossRef Medline

West DC, Lovick TA, Wolstencroft JH (1982) An excitatory input to nucleus raphe magnus from the red nucleus in the cat. Neurosci Lett 29:31-34. CrossRef Medline

Whishaw IQ, Pellis SM, Gorny B, Kolb B, Tetzlaff W (1993) Proximal and distal impairments in rat forelimb use in reaching follow unilateral pyramidal tract lesions. Behav Brain Res 56:59-76. CrossRef Medline

Whishaw IQ, Gorny B, Sarna J (1998) Paw and limb use in skilled and spontaneous reaching after pyramidal tract, red nucleus and combined lesions in the rat: behavioral and anatomical dissociations. Behav Brain Res 93: 167-183. CrossRef Medline

Williams PT, Kim S, Martin JH (2014) Postnatal maturation of the red nucleus motor map depends on rubrospinal connections with forelimb motor pools. J Neurosci 34:4432-4441. CrossRef Medline

Yiu G, He Z (2006) Glial inhibition of CNS axon regeneration. Nat Rev Neurosci 7:617-627. CrossRef Medline

Z'Graggen WJ, Metz GA, Kartje GL, Thallmair M, Schwab ME (1998) Functional recovery and enhanced corticofugal plasticity after unilateral pyramidal tract lesion and blockade of myelin-associated neurite growth inhibitors in adult rats. J Neurosci 18:4744-4757. Medline

Z'Graggen WJ, Fouad K, Raineteau O, Metz GA, Schwab ME, Kartje GL (2000) Compensatory sprouting and impulse rerouting after unilateral pyramidal tract lesion in neonatal rats. J Neurosci 20:6561-6569. Medline 